\title{
6 Passerine Station Laboratory Methods
}

\subsection{Species Determination and Coding}

Species determination is undoubtedly a fundamental starting-point for ringing. For ringing purposes, a good key or "the bird in the hand" type of manual should be used. Common "guides to...", coloured books for field identification of birds are based on characters visible from a distance, frequently including behaviour and bird voices. These sometimes could be insufficient for correct determination of an individual catch; some field characters are no longer visible at the bird with disturbed plumage, and the voice of the bird crying when removed from the net have no similarities to natural calls. On the other hand, "the bird in the hand" manuals present speciesspecific characteristics, which are completely invisible in the field, e.g. details of wing-formula or colour patterns of single feathers. These details should be carefully noted when rare species or species difficult to determine are ringed.

There are two main types of determination procedures in use: a key system where alternative characters are listed in hierarchical order, usually a dichotomous form and guide system, where alternatives of different characters are given as sometimes long text describing more or less important details. The first, traditional system is easier to handle for less experienced workers that are guided to final decisions by the construction of the key. However, misunderstanding one step in the key sequence (or misunderstanding the description given) could lead to wrong species determination. This key determination must be confirmed by a careful study of the species description given in the guide form. Any doubts should be clarified in the early stages of discrimination. Guide systems are good for experienced ringers who are well acquainted with the guides' manner of description and for ringers who know which characteristics are the most important ones in the family of the individual caught. There is less confusion, and if there is any contradiction between characters, it is easier to assess the relative value of the characters in question.

Correctly identified bird species must be correctly noted in the ringing form. Because of the inconveniences of plain text writing, for ringers as well as for the person who loads collected data into data-file, different forms of species name codes are in use. They render the species name in a short form that is easy to write down under field conditions and is not time-consuming when typed on a keyboard.

For mnemotechnical reasons, any number code must be excluded from the field use; letter codes are easier to remember and less vulnerable to errors. The most universal in the international network is a five or six-letter codes based on scientific names and specially prepared to be error-proof. The main idea is construction of the code in two segments - two (in 5-letter code) opening letters from the scientific genus name or three (in 6-letter code) e.g. PA or PAR (from Parus) and three 
FIRST letters from the species name, e.g. MAJ (from major) - that gives PAMAJ (5-letter code) or PAR.MAJ (6-letter code) for Parus major. However, this simple, standard rule can sometimes lead to identical codes given to different species, e.g. PHYlloscopus TROchilus and PHYlloscopus TROchiloides or ACRocephalus PALudicola and ACRocephalus PALustris, so in these cases, other procedures must be used. The additional, B-procedure uses three opening letters from the generic name and three LAST letters from the species name, thus the above-mentioned Phylloscopus trochilus is coded as PHYLUS, while Phylloscopus trochiloides as PHYDES. Note that code PHYTRO is not used anymore, since it is meaningless. Additionally, this procedure should be applied for coding the species that could have standard codes very similar when hearing by a person noting the ringing data into the ringing form, e.g. 6-letter code for Calidris alba using standard procedure would be CAL.ALB, while code for Calidris alpine, CAL.ALP, sounds very similar and erroneous codes could be easily written. To avoid typing errors when inputing data from a keyboard some codes differentiated only by one letter - being close to other one at the keyboard, e.g. TRI.FLA and TRI.GLA as F and $\mathbf{G}$ are side by side on the keyboard, are differentiated using the B-procedure, described above. Even the B-procedure does not solve all problems; some species codes that are created by the A-procedure are identical or very similar to other codes. To solve the last of the remaining problems after trial of B-procedure must be solved by C-procedure: using as the second part of the code three letters from the species name, but neither the first nor last ones, e.g. CARduelis flaVIRostris. Among all bird species listed in the EURING list of species, supplemented by species that can be normally found in the Middle East, there are 555 standard codes, 51 B-procedure codes and 8 C-procedure codes. The special procedure codes, as well as group codes, for visual observations are listed in Tables 6.1-6.2. If letter codes are used outside of the Western Palaearctic and the Middle East, local code sets must be elaborated and checked for possible doubling of codes and possibility of errors. Note that during last years, a number of genus names have been changed and the process is still causing troubles to many field ornithologists who are not familiar with current taxonomical developments. It must be taken into consideration whether introduction of the code sourced in the new name does not double the existing one and decide to create new code after B- or C-procedure instead. The same problem is with new species names when the wellknown species is split into two or more items. E.g., separation two subspecies of the Stonechat (coded as SAX.TOR) - Saxicola torquata rubicola and S. t. mauri - into full species $S$. rubicola and $S$. mauri, that could be coded according to A-procedure as SAX.RUB and SAX.MAU accordingly, made the first code meaningless because of already existing code SAX.RUB for the Whinchat, Saxicola rubetra. This changed coding of Whinchat and European Stonechat to SAX.TRA and SAX.OLA, according to B-procedure. 
Summarising, the species 5- and 6-letter codes are created in the following standard way:

Genus code: FIRST TWO (5-letter code) or FIRST THREE (6-letter code) letters of the genus scientific name.

The basic procedure A: genus code + FIRST three letters of the scientific species name,

The procedure B: genus code + LAST three letters of the scientific species name, The procedure C: genus code + three OTHER than above letters of the scientific species name.

Non-standard code items, constructed according to special procedures: B and C, are listed in Table 6.1 and the group observation codes, for the birds not identified to the species level, listed in Table 6.2.

Table 6.1: List of non-standard code items according to:

B-procedure (genus code + three LAST letters of species name)

\begin{tabular}{lll}
\hline & 5-letter code & 6-letter code \\
\hline Acrocephalus paludicola & ACOLA & ACR.OLA \\
Acrocephalus palustris & ACRIS & ACR.RIS \\
Calandrella rufescens & CAENS & CAL.ENS \\
Calidris alba & CAALB & CAL.LBA \\
Calidris alpina & CAALP & CAL.INA \\
Calidris canutus & CATUS & CAL.TUS \\
Calidris fuscicollis & CALIS & CAL.LIS \\
Calidris minuta & CAUTA & CAL.UTA \\
Calidris minutilla & CALLA & CAL.LLA \\
Caprimulgus ruficollis & CALIS & CAP.LIS \\
Carduelis cannabina & CACAN & CAR.INA \\
Carduelis carduelis & CACAR & CAR.LIS \\
Carduelis flammea & CAMEA & CAR.MEA \\
Chettusia leucura & CHURA & CHE.URA \\
Chlidonias leucopterus & CHRUS & CHL.RUS \\
Corvus c. cornix & CONIX & COR.NIX \\
Corvus corax & CORAX & COR.RAX \\
Corvus corone & COONE & COR.ONE \\
Cyanistes cyanus & CYNUS & CYA.NUS \\
Cyanopica cyana & CYANA & CYA.ANA \\
Emberiza pusilla & EMLLA & EMB.LLA \\
Emberiza rustica & EMICA & EMB.ICA \\
Ficedula narcissina & FIINA & FIC.INA \\
\hline & & \\
\hline
\end{tabular}


continued Table 6.1: List of non-standard code items according to:

\begin{tabular}{lll}
\hline & 5-letter code & 6-letter code \\
\hline Ficedula parva & FIRVA & FIC.RVA \\
Lanius minor & LANOR & LAN.NOR \\
Locustella luscinioides & LODES & LOC.DES \\
Luscinia luscinia & LUNIA & LUS.NIA \\
Milvus migrans & MIANS & MIL.ANS \\
Milvus milvus & MIVUS & MIL.VUS \\
Oenanthe leucopyga & OEYGA & OEN.YGA \\
Oenanthe leucura & OEURA & OEN.URA \\
Phasianus colchicus & PHCUS & PHA.CUS \\
Phylloscopus trochiloides & PHDES & PHY.DES \\
Phylloscopus trochilus & PHLUS & PHY.LUS \\
Podiceps cristatus & POTUS & POD.TUS \\
Podiceps grisegena & POENA & POD.ENA \\
Porphyrio porphyrio & PORIO & POR.RIO \\
Porzana porzana & POANA & POR.ANA \\
Pyrrhocorax pyrrhocorax & PYRAX & PYR.RAX \\
Pyrrhula pyrrhula & PYULA & PYR.ULA \\
Saxicola rubetra & SATRA & SAX.TRA \\
Saxicola rubicola & SAOLA & SAX.OLA \\
Stercorarius parasiticus & STCUS & STE.CUS \\
Sterna paradisaea & STAEA & STE.AEA \\
Sylvia conspicillata & SYATA & SYL.ATA \\
Sylvia melanocephala & SYALA & SYL.ALA \\
Sylvia melanothorax & SYRAX & SYL.RAX \\
Tetrao tetrix & TERIX & TET.RIX \\
Tetrax tetrax & TERAX & TET.RAX \\
Tringa flavipes & TRPES & TRI.PES \\
Tringa glareola & TROLA & TRI.OLA \\
\hline & & \\
& & \\
\hline
\end{tabular}

C-procedure (genus code + three not FIRST nor LAST letters of species name)

\begin{tabular}{lll}
\hline & 5-letter code & 6-letter code \\
\hline Carduelis flavirostris & CAVIR & CAR.VIR \\
Ficedula albicollis $x$ hypoleuca & FIAXH & FIC.AXH \\
Larus minutus & LAUTU & LAR.UTU \\
Parus montanus & PAUMO & PAR.UMO \\
Passer montanus & PASMO & PAS.SMO \\
Phylloscopus collybita & PHBIT & PHY.BIT \\
Sylvia communis & SYUNI & SYL.UNI \\
\hline
\end{tabular}


Table 6.1: List of non-standard code items according to:

OLD-codes (codes used in the past)

\begin{tabular}{|c|c|c|}
\hline & 5-letter code & 6-letter code \\
\hline Acrocephalus paludicola & ACPALA & \\
\hline Acrocephalus palustris & ACPALS & ACR.UST \\
\hline Acroceplalus palustris & ACUST & ACR.UST \\
\hline Acrocephalus schoenobaenus & & ACR.ENO \\
\hline Acrocephalus scirpaceus & & ACR.IRP \\
\hline Calidris minutilla & CAMINL & CAL.LLA \\
\hline Carduelis flammea & CAFLAM & \\
\hline Carduelis flavirostris & CAFLAV & \\
\hline Emberiza pusilla & EMPUS & \\
\hline Emberiza rustica & EMRUS & \\
\hline Ficedula narcissina & FINAR & FIC.NAR \\
\hline Ficedula parva & FIPAR & FIC.PAR \\
\hline Larus minutus & LANUT & LAR.NUT \\
\hline Locustella luscinioides & LOLUS & LOC.LUS \\
\hline Luscinia luscinia & LULUS & LUS.LUS \\
\hline Mergus merganser & MEMER & MER.GAN \\
\hline Mergus serrator & MESER & MER.RAT \\
\hline Milvus migrans & MIMIG & \\
\hline Milvus milvus & MIMIL & \\
\hline Phasianus colchicus & PHCOLS & PHA.COL \\
\hline Phylloscopus collybita & PHCOL & PHY.COL \\
\hline Phylloscopus trochiloides & PHTROO & \\
\hline Phylloscopus trochilus & PHTROU & \\
\hline Podiceps cristatus & POCRI & POD.CRI \\
\hline Podiceps grisegena & POGRI & POD.GRI \\
\hline Pyrrhocorax pyrrhocorax & PYPYRX & \\
\hline Pyrrhula pyrrhula & PYPYR & \\
\hline Saxicola rubetra & SARUB & SAX.RUB \\
\hline Saxicola torquata & SATOR & SAX.TOR \\
\hline Stercorarius parasiticus & STPARS & STE.SIT \\
\hline Sterna paradisaea & STPARA & STE.AEA \\
\hline Sylvia communis & SYCOM & SYL.COM \\
\hline Sylvia conspicillata & SYCON & SYL.CON \\
\hline Tetrao tetrix & TETETI & \\
\hline Tetrax tetrax & TETETA & \\
\hline Tringa flavipes & TRFLA & TRI.FLA \\
\hline Tringa glareola & TRGLA & TRI.GLA \\
\hline
\end{tabular}


Table 6.2: Group observation codes, used when the birds are not fully identified

\begin{tabular}{ll}
\hline Group & Code \\
\hline Accipiter sp. & ACC \\
Anser sp. & ANS \\
Anthus sp. & ANT \\
Branta sp. & BRA \\
Buteo sp. & BUT \\
Circus sp. & CIR \\
Columba sp. & COL \\
Corvus sp. = Corvidae & COR \\
Falco sp. & FAL \\
Fringilla sp. & FRI \\
Fringillidae & FEE \\
Hirundinidae & HEE \\
Loxia sp. & LOX \\
Motacilla sp. & MOT \\
Parus sp. & PAR \\
Passer sp. & PAS \\
Passeriformes & PSS \\
Streptopelia sp. & STR \\
Turdus iliacus/philomelos & TUR \\
\hline & \\
\hline
\end{tabular}

\subsection{Sex/Age Determination and Coding}

In modern ringing, sexing and ageing of ringed birds is a rule. However, contrary to the species determination, it is sometimes impossible to determine, or the criteria do not allow full separation. Despite this weakness, sex and age determination should be performed in as many cases as possible. Where possible, species-specific characters should be used according to appropriate manuals. As in the case of species determination, key or guide procedures could be used. In the cases of sex and age determination, where different characters are more diversified in terms of their utility and simplicity to apply, the key system has some additional advantages. It is a psychological rule, that beginners use their own intuition, which could be far from optimal, in sex and age identification, especially when confronted with a few unprecedented characters. Since not everyone knows these solutions, the results of identifications made by different ringers may have different degrees of validity. They depend on the leading character accepted by the ringer and need not be fully compatible. On the other hand, a hierarchy of characters instituted by an experienced specialist and presented as a key hierarchy has a chance of being optimal. 
Since most age characters are connected with the bird plumage, the age coding is derived from the names of subsequent plumages, which are identifiable (Figure 6.1):

J - juvenile plumage: the bird in its first full plumage; feathers grown in the nest or first feathers following down-plumage

I - mixed immature plumage: plumage containing some juvenile feathers and some renewed feathers of the next set

A - definite (adult) nuptial plumage, $\mathbf{D}$ - adult postnuptial plumage

$\mathbf{N}$ - not defined plumage, but not juvenile plumage

L or “-” - full-grown, not checked for plumage type. For some species with more complicated pattern of plumage development, a few other, detailed codes could be used:

$\mathrm{S}$ - first full immature plumage: second full plumage

$\mathrm{T}$ - second full immature plumage: third full plumage

$\mathrm{M}$ - immature plumage, precise type (I, S, T) is unknown

$\mathrm{O}$ - not adult plumage (either juvenile or any immature one)

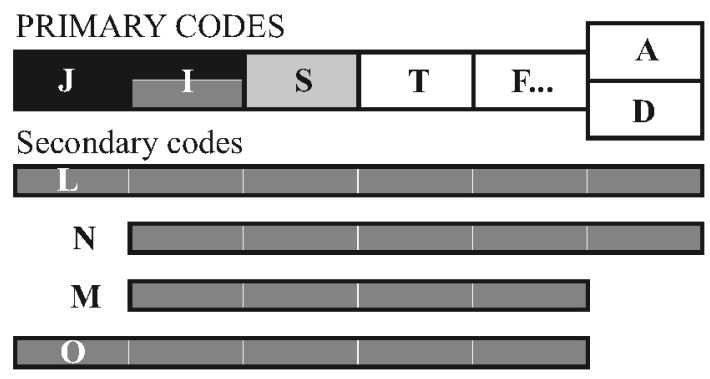

Figure 6.1: Plumage coding system (explanations in the text). Secondary codes are used when the exact plumage is not known. They could contain different combination of plumage classes as shown at the bottom of the Figure.

Apart of the age coding system based on the plumage (codes given above), a system called "calendar years" is also used by ringers. In this system, a young bird (from this year's brood) is called "1st year bird", while its parents are in "after 1st year". It seems simple, but the first year lasts only till December 31st, so has a length of few months (in Europe), while it can last a few days only in the tropics and on the southern hemisphere, where breeding time is around December/January. From the 1st of January the same bird called earlier as "1st year" must be described as being in " 2 nd year" and its parents as "after 2nd year". The next change of the age name is when birds leave nests, our "2nd year" bird is named as "after 1st year", while its parents become apparently younger, written as "after 1st year" instead of "after 2nd year". The next complication due to the 
differential coding of "ages" in different countries: as number codes (EURING, Great Britain) or after local languages (e.g. "1", “2”, “po 1”, "po 2” in Poland or 2, 4, 5 and 6 in Italy). The codes used in official EURING system are as shown in the Table 6.3.

Table 6.3: EURING age codes.

\begin{tabular}{|c|c|}
\hline $\begin{array}{l}\text { EURING } \\
\text { code }\end{array}$ & \\
\hline 0 & Age unknown, i.e. not recorded. \\
\hline 1 & Pullus: nestling or chick, unable to fly freely, still able to be caught by hand. \\
\hline 2 & Full-grown: able to fly freely but age otherwise unknown. \\
\hline 3 & First-year: full-grown bird hatched in the breeding season of this calendar year. \\
\hline 4 & $\begin{array}{l}\text { After first-year: full-grown bird hatched before current calendar year; year of birth other- } \\
\text { wise unknown. }\end{array}$ \\
\hline 5 & 2nd year: a bird hatched previous calendar year and now in its second calendar year. \\
\hline 6 & $\begin{array}{l}\text { After } 2 \text { nd year: full-grown bird hatched before previous calendar year; year of birth } \\
\text { otherwise unknown. }\end{array}$ \\
\hline 7 & 3rd year: a bird hatched two calendar years before, and now in its third calendar year. \\
\hline 8 & $\begin{array}{l}\text { After 3rd year: a full-grown bird hatched more than three calendar years ago (including } \\
\text { present year as one); year of birth otherwise unknown. }\end{array}$ \\
\hline 9 & 4th year: a bird hatched three calendar years before, and now in its fourth calendar year. \\
\hline A & After 4th year: a bird older than category 9 - age otherwise unknown. \\
\hline B & $\begin{array}{l}\text { 5th year: one year older than category } 9 \text { - age known exactly to the year. C, D, E, F, G, H, J, } \\
\mathrm{K}, \mathrm{L} \text {, etc. onwards et seq. }\end{array}$ \\
\hline
\end{tabular}

In the sex coding only letters $\mathrm{M}$ (male) and $\mathrm{F}$ (female) or scientific signs ( $\delta$ and + ) should be used - any number coding ( 0 and 1, 1 and 2, 2 and 1 ) easily leads to errors!

\subsection{Standard Set of Measurements}

First, one general comment: It must be emphasized that a single measurement of a ringed individual is of very low value to the study of population differentiation among migrants, their breeding origin, or even of sex and age dimorphism. Despite common beliefs, a measurement of e.g. only wing-length certainly does not present adequate information on "the size of the bird". Different measurable bird size parameters including wing-length, feather-length, tail-length and body mass are sometimes not positively correlated when birds of different origin are compared. These parameters often change independently over the breeding range, so we may be confronted with e.g. long-winged and short-tailed birds at one station, and short-winged and longtailed at another. At the same time, body mass depends very much on fat reserves of an individual, and heavier, but fatty, birds may still have lower lean body mass than other individuals, which were weighed as lean birds. Arrangement of measurements 
into carefully selected standard sets allows us to conduct much more detailed biometric studies. These sets may be different in e.g. passerines and waders.

A recommended standard set of measurements for passerines contains wingand tail-length, wing formula, fat score and body mass. For standards applicable to waders see, Wader Station Laboratory Methods (p. 148).

\subsection{Standard Descriptions of Measurements}

Note that standard bird handling (described earlier) is assumed for all of the procedures recommended here. The ruler of $30 \mathrm{~cm}$ long and cut off at the zero-line is the standard tool for wing, wing-formula and tail measurements.

Within descriptions of alternative methods (see Alternative Methods of Holding and Measuring Birds, p. 184) the manner of handling could be different, and other types of rulers could be used.

Wing-length (maximum chord measurement)

Both the ruler with and without a stop can be used, as they give exactly the same results.

\section{Technique}

The folded wing, parallel to the body axis, rests on a ruler (Figure 6.2-6.3). The carpal joint of the wing is placed at the butt of the ruler; if the ruler has no stop, cut off at the zero-point, using the bulb of the second finger of the right hand. With the thumb of the same hand, the wing is firmly but carefully pressed against the ruler; at the same time, the thumb of the left hand straightens the primaries to their maximum length by smoothing the lateral curvature and applying slight lateral pressure towards the bird's body at the level of the primary coverts. The third and fourth fingers of the left hand control folding and straightening of the wing.

Precision of measurement: $1 \mathrm{~mm}$

The most common mistakes in measurement:

Wing-length underestimated:

- The wing not fully pressed to the ruler, the primaries not fully straightened.

Wing-length overestimated:

- The carpal joint not taken fully to the butt of the ruler (this is much more probable when a ruler with a stop is used).

- The carpal joint is not bent enough, and bones of forearm are included in measurement.

Other techniques - see Alternative Methods of Holding and Measuring Birds, p. 184. 


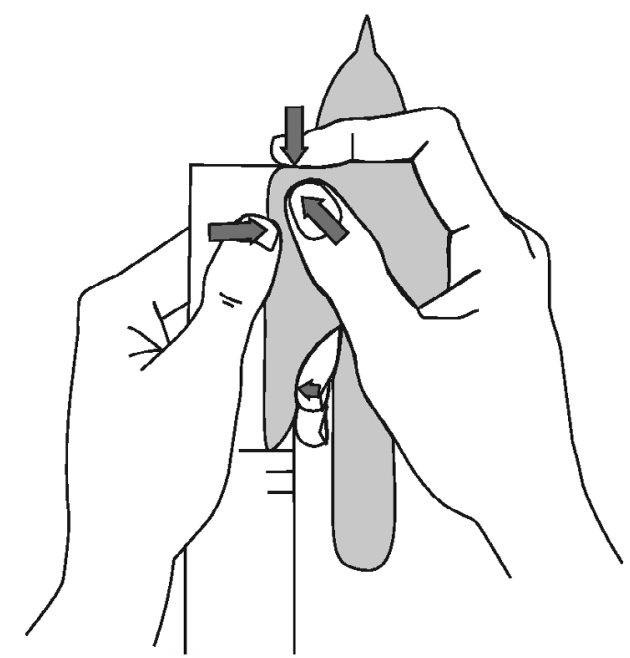

Figure 6.2: Standard measurement of the wing-length (critical elements of the procedure pointed by arrows).

Wing-formula measurement (feather tips distances method)

The wing-formula includes measurements of distances from the wing point to the tips of the shorter primaries. The primaries from the second to the eighth (in ascending order) are taken into consideration (Figure 6.3); for simplicity, the first functional primary is always numbered as second, irrespective of its "evolutionary" number (even in families e.g. Motacillidae, Fringillidae, etc., which have lost their first short primary).

Use of a ruler with a zero-stop is not convenient, though possible.

An example wing (Figure 6.4): the tip of the wing is formed by primaries 4th and 5th; 3rd primary tip is by $1 \mathrm{~mm}$ shorter than the wing-tip, $6 \mathrm{th}-2 \mathrm{~mm}$, 2nd is equal to the 7th and they are shorter by $6 \mathrm{~mm}$, 8th is $9 \mathrm{~mm}$ shorter.

For recording purposes, this formula would be spoken as: "four to fifth, zero-one, two, six-six, nine". The record in subsequent boxes of the form:

|45|01|2|6|6|9| |

"Zero" (in box 2) is written as an indicator for special processing. Explanations of spoken recording:

1. In the first box - the numbers of the longest primaries are called out,

2. In the next boxes - distances (in full $\mathrm{mm}$ ) between the tips of primaries and the tip of the wing.

(1) "fourth to fifth" indicates that primaries 4 and 5 form the tip of the wing (4=5). Other possibilities in this box: (A.) only one number (e.g. "third" - means that the tip of the wing is formed by one primary only (the third); (B.) two not consecutive numbers (e.g. "fourth to sixth" means $4=5=6$, "third to sixth" - $3=4=5=6$ ). 


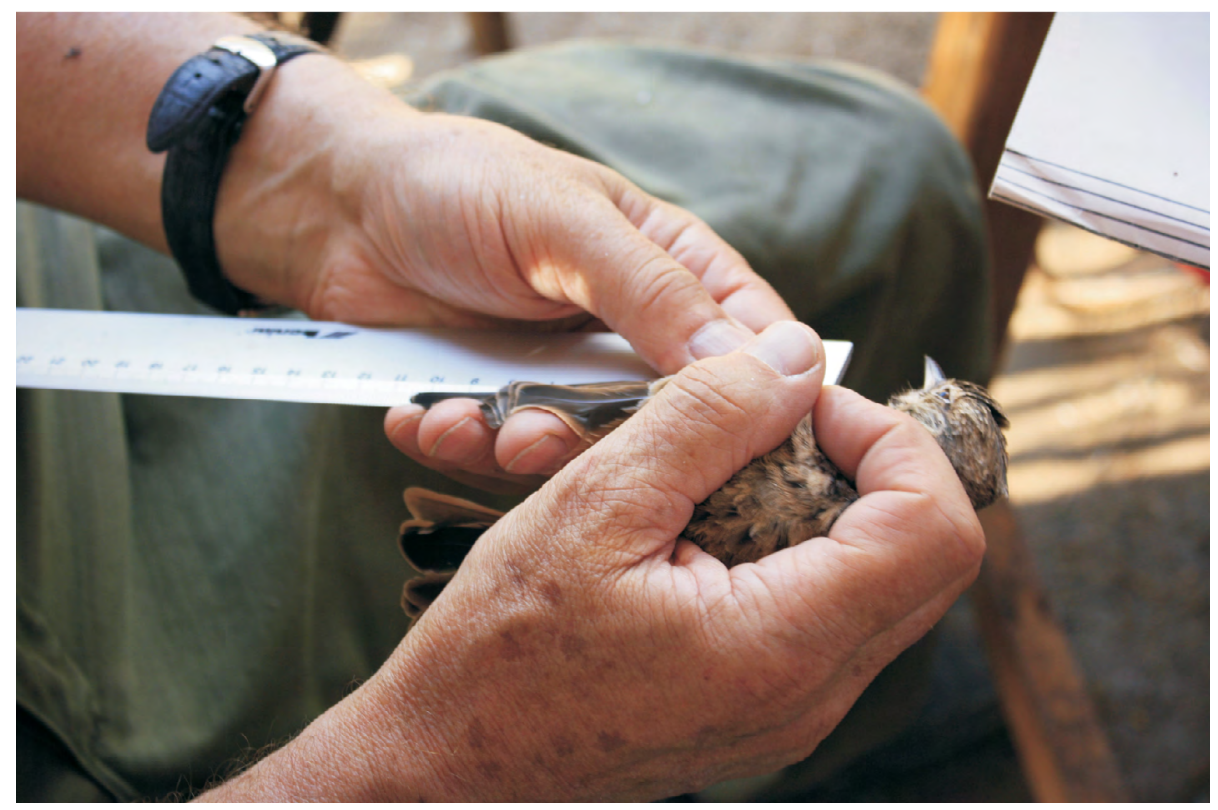

Figure 6.3-1: Measurement of the wing-length taken using a ruler without stop. Photo unknown.

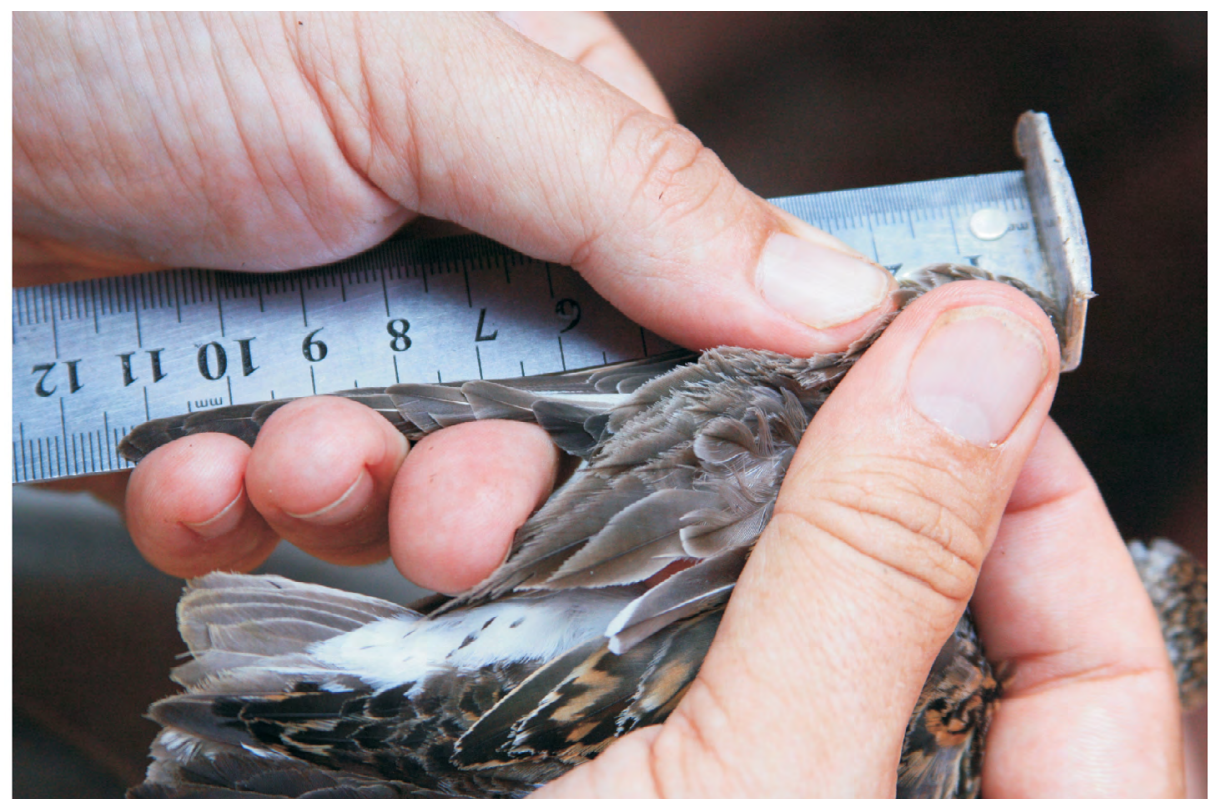

Figure 6.3-2: Measurement of the wing-length taken using a ruler with stop. Photo unknown. 


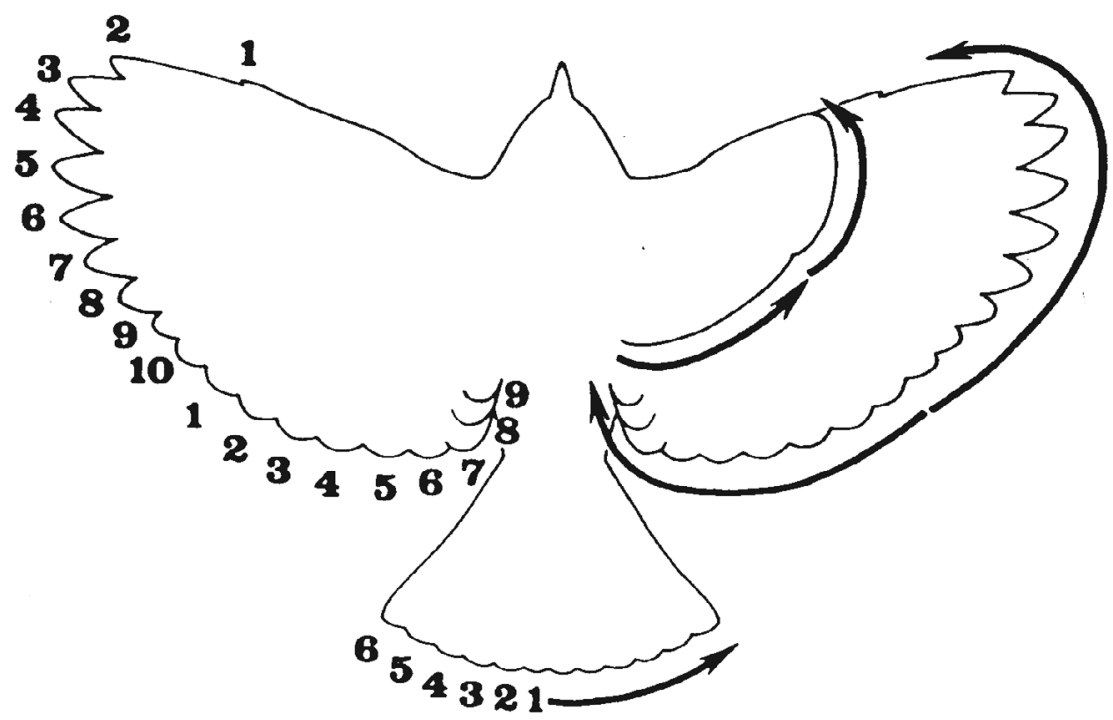

Figure 6.4: Ascendant numbering of primaries and rectrices. Typical moult directions are shown at the right side of the drawing.

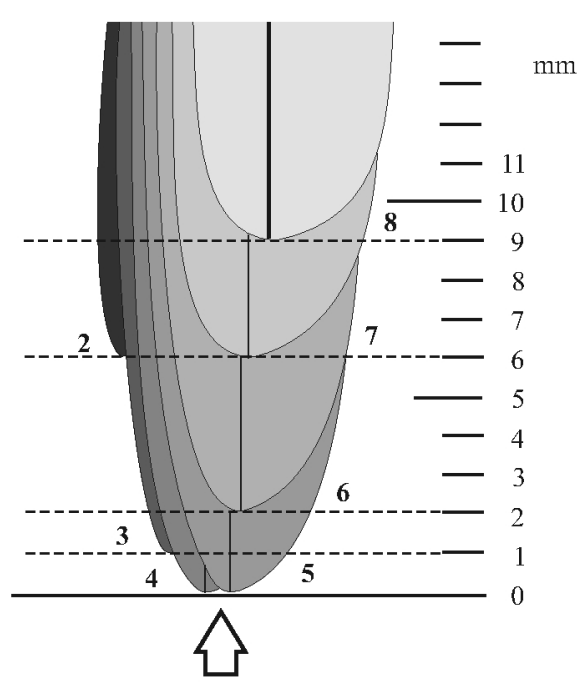

WING TIP

Figure 6.5: The wing-formula measurement (example used in text). Note that this is NOT an illustration of the technique of the measurement (see Figure 6.7). 
(2) "zero-one" - the word "zero" indicates that the measurement given is of the distal primary (i.e. placed distally in relation to the longest ones; in this formula the "distals" are the second and third primaries and the "proximals" - 6th, 7th and 8th; when the distal primary is equal with the proximal one, the word "zero" is omitted (e.g. "six-six" - later in this formula).

(3) "two" and "nine" - the measurements of the proximal primaries.

Note: if someone would like to measure all primaries - till the 10th - two more boxes should be added into the layout shown above.

\section{Technique (Figure 6.6)}

1. Count the number(s) of the longest primary(ies) when the wing is closed before measuring spread and extending the left wing to check the state of the feathers for cleanliness, moult, loss or damage (and to check that they follow in correct sequence).

2. Fix the closed wing in its natural position (as natural as possible), holding it almost parallel to the body axis (looking from the back side) by holding with the first and second fingers of the right hand near the carpal joint so that the primaries cannot change their position during the measurement procedure.

This is the most difficult and critical part of the technique.
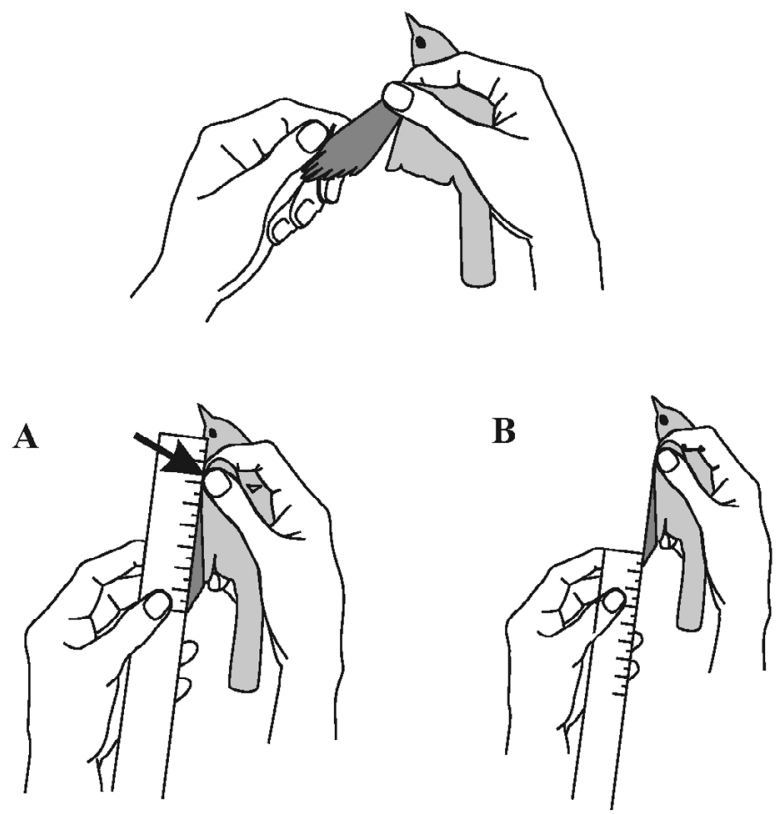

Figure 6.6: Technique of the wing-formula measurement. Clearing the feathers sequence (above) and two variants ( $A$ and $B$ - see text) are shown (below). 
3. Measure the wing-formula with the methods A or B (see below). To measure the distal primaries move the hand with the bird in relation to the fixed ruler position.

A: the edge (the zero-end) of the ruler is placed at the tip of each primary sequentially from the wing tip. After each value has been recorded, the ruler's end is moved to the next primary tip.

$\mathrm{B}$ : the tip of the wing is put at any centimetre-line of the ruler (convenient for the size of the bird) and the values are taken in the opposite direction from that normally used.

These two methods are compatible, but Method A is slower and more vulnerable to mis-readings. Thus, Method B is generally recommended. If the same person is measuring wing-formula and recoding it into a notebook, it is highly advisable to measure and memorize the whole formula at once and then write it at once, too.

Precision of measurements: $1 \mathrm{~mm}$

The most common mistakes in measuring:

Mistakes mainly result from inaccurate handling of the bird:

- The head of the bird is pulled back between fingers, and

- The wing is extended too much and not firmly fixed between the first and second fingers.

When method B is used, the position of the wing tip on the ruler may change, causing inaccurate measurements if the ruler is not fixed (in relation to the hand holding the bird).

Comments to the other method - see Alternative Methods of Holding and Measuring Birds, p. 184

Tail-length measurement (“to the back” method after Busse, 1983; 1990)

Measurement of the tail with the pygostyl: a simple, very quick and safe method for the bird. The ruler with the stop cannot be used.

\section{Technique}

The body of the bird is held vertically with the tail directed at right angle $\left(90^{\circ}\right)$ to the back (Figure 6.7). The ruler lies at the tail with the butt pressed firmly to the back (controlled with the fourth and the fifth finger under the belly). The restrices should touch the ruler along their whole length. The longest tail feather measurement is read.

Generally, tail length measurements are more difficult to be taken correctly, so special attention should be put on bolded remarks in the description.

Precision of measurement: $1 \mathrm{~mm}$ 


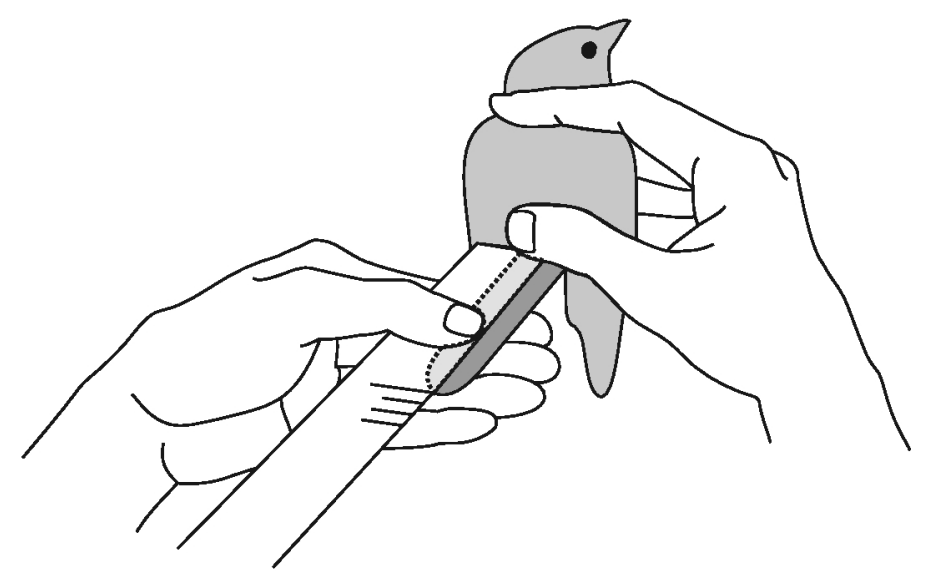

Figure 6.7: Technique of the tail-length measurement (note perpendicular position of the birds back in relation to the ruler).

The most common mistakes in measurement:

Tail-length underestimated:

- An acute angle made between the tail and the back; the bird body too close to the ruler).

- The ruler end not firmly located (the fourth and the fifth fingers do not press the belly).

- Restrices do not touch the ruler along their whole length (not pressed to the ruler by the fingers of the left hand).

- False reading of some mm will result if the butt of the ruler is at the tip of the pygostyl instead of at the bird's back.

Tail-length overestimated:

- An obtuse angle made between the tail and the back; the bird body too far from the ruler.

- The butt of the ruler touches the bird's back well above the pygostyl instead of laying on it.

Other techniques - see Alternative Methods of Holding and Measuring Birds, p. 184.

Fat determination (after Busse, 1983 and Kaiser, 1993, combined)

Determination of fat goes through three levels (Figure 6.8):

Level I - belly

Level II - furculum

Level III - pectoral muscles 


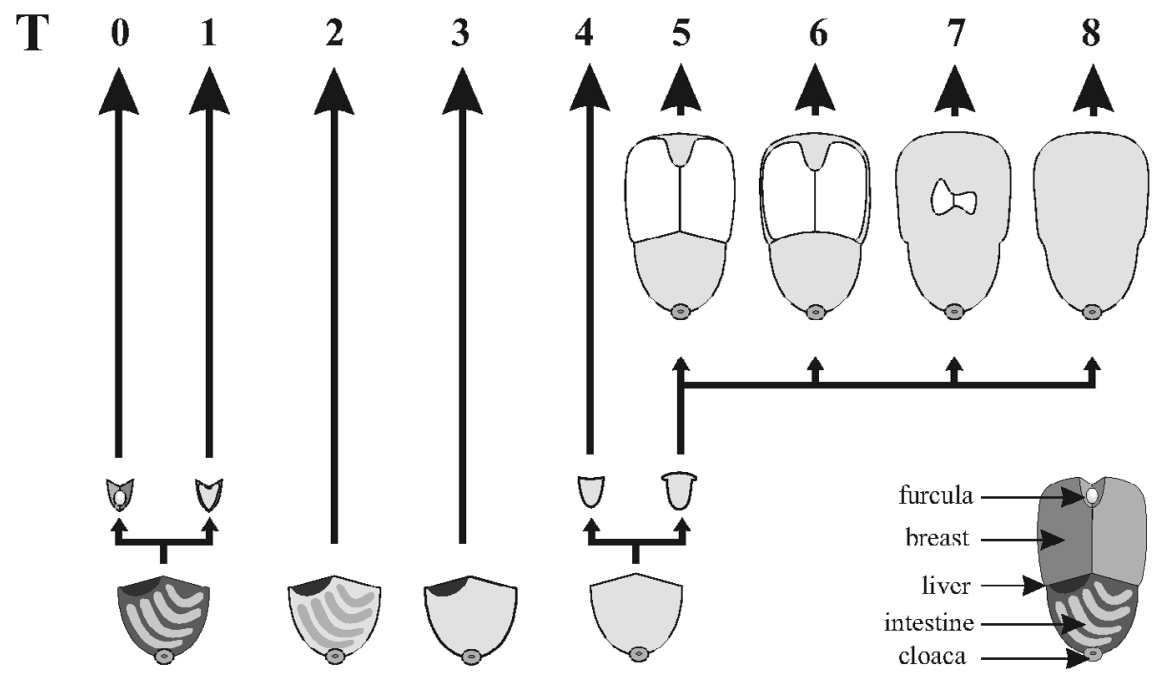

Figure 6.8: Fat scores (description in the fat-scoring key on p. 95).

Key to fat determination:

I. 1. Belly is without visible fat or with reddish traces only - II A

2. Belly with infused bands of fat (intestinum is visible) $\mathbf{T 2}$

3. Belly has a fused cover of fat; intestinum is not but the liver is visible T3

4. Belly is completely covered with fat, a very narrow band of the liver may be visible but, if this is so, the roll of fat is just above it - II B

II A. 1. Air -sack is visible within furculum (some fat may occur) T0

2. All the interior of furculum is covered with fat

T1

II B. 1. Fat in furculum flat or concave T4

2. Fat in furculum forms a convex cushion - III

III. 1. Sides of pectoral muscles without strips of fat T5

2. Sides of pectoral muscles with strips of fat T6

3. Pectoral muscles partly covered with fat T7

4. Pectoral muscles completely covered with fat T8

Note: In some species, loss of fat does not follow exactly the same sequence in which it was attained, this results in problem with fat determination in some specimens. Anyhow, always follow exactly the key, as specific differences are covered by speciesspecific validation of the scale. 


\section{Technique:}

1. Lay the bird on its back on the palm (Figure 6.8); the neck should be between the second and third fingers of the hand; the second and the third fingers of the second hand should gently part the bird's legs; the proper position of bird is very important. 2. Blow the belly (Figure 6.8A) with a continuous stream of air and choose one of four possibilities under section I of the key; if the second or third subsection is chosen you have determined the fatness as T2 or T3 respectively.

3. If II A or II B are chosen, you must direct your blowing to the furculum (Figure 6.9B) and choose one of the two subsections under II A (fatness T0 or T1) or II B (fatness T4 or higher - III).

4. If your choice is III, look at pectoral muscles and choose fatness T5 - T8.

The most common mistakes:

Mistakes are usually made when someone has a tendency to take "liberal" interpretation of rules, e.g. when the bird has a thick cover of yellow fat on the belly but part of the intestinum visible; this should be T2 but is classified as T3 because it "looked like a fatty bird". Some mistakes are possible when the bird is not properly handled when the furculum contents are evaluated.

Note that the fatness of an individual bird properly determined twice at the same time may be different. This is because in border cases, different tension of the bird's belly muscles at the moment of blowing may expose (or not expose) the intestinum or the liver from under the fat layer. Difference in determination cannot, however, exceed one degree of fatness.

A

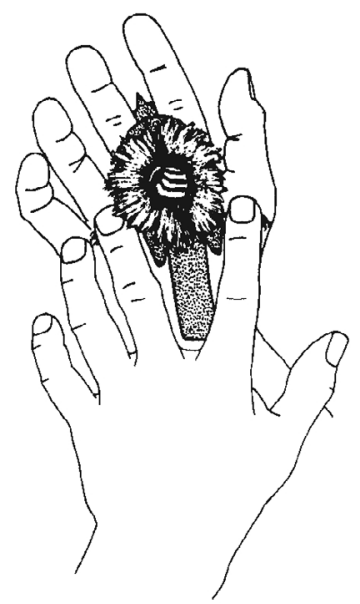

$\mathrm{B}$

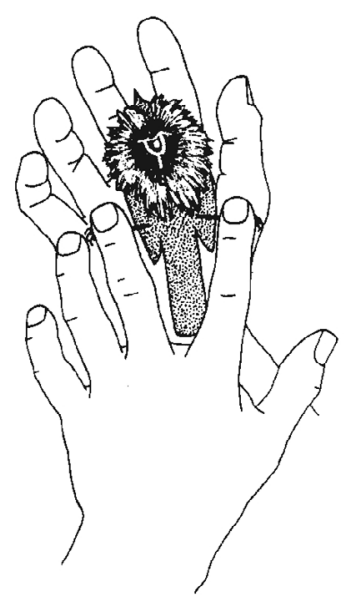

Figure 6.9: Technique of the fat scoring. A - blowing to the belly, B - blowing to the furcular depression. 


\subsection{Additional Measurements and Scores}

Additional measurements and scores can be used optionally.

\section{Feather-length of the third outermost primary}

Description from Manual of Field Methods (Bairlein, 1995): “Measuring feather-length takes little time and can be accurately done when the following instructions are observed (Figure 6.10):

Use a ruler with vertical pin of exactly $1.4 \mathrm{~mm}$ diameter (Figure 3.7 (3)).

The ruler has to be fixed onto a block of wood or onto the table and the bird has to be held with both hands. Do not hold the ruler free-hand. By using this method the inter-observer variance of the measurement is significantly reduced.

Hold the wing at the carpal joint between your thumb and index finger. Take the second outermost primary (F9) with the other hand and open the wing slightly and place the pin between 2nd and 3rd outermost primaries until it firmly touches the skin. This point is easily found and well defined.

The primary now has to be completely straightened by first bending it outward a little (to get maximum length). The length is read to the nearest $0.5 \mathrm{~mm}$.

Make sure not to interfere with primary coverts, i.e. the primary covert should be on the same side of the pin as the corresponding primary.

Do not use excessive force, and be as cautious as possible to avoid any injuries."

Comments: The method presented, although it seems very exact, has a number of disadvantages. First of all, the first measurement cannot be repeated on the same individual as the second, and subsequent measurements are regularly 0.5 to $1 \mathrm{~mm}$ longer. These are corrected for during calibration courses in which trained ringers participate; this means that there is no way to control for whether the newly trained person measures

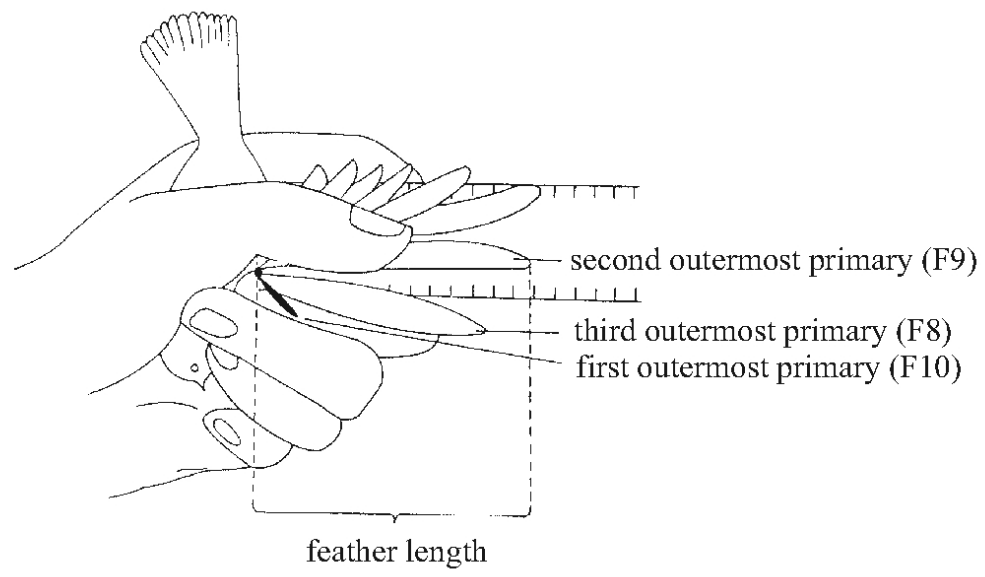

Figure 6.10: Technique of the feather-length (after Vogelwarte Radolfzell, from Bairlein, 1995). 
the bird correctly or not. Secondly, the diameter of the pin $(1.4 \mathrm{~mm})$ is much too thick to measure the feather-length in small passerines (a distance between primaries at the level where they go out from the skin is around $0.2 \mathrm{~mm}$ ). Thus, there remains the possibility to use the excessive power to press the pin until it firmly touches the skin, and when a $1.4 \mathrm{~mm}$ thick pin is pressed into a fissure that is several times narrower, the skin may be broken or slipped along the feather shaft. Subsequent measurements show that this is not only a theoretical speculation. Discussion of the method by Gosler et al., (1995) shows that it should not replace wing-length as a standard measurement.

\section{Wing-shape measurement}

The wing-shape measurement as described in Manual of Field Methods (Bairlein 1995): "To measure wing-shape, the length of each individual primary (except the outermost F10) and the first secondary is measured using the feather-length ruler and the method described above (feather-length measurement). With the exception of primary 9 (F9, the second outermost), which has to be measured with the pin inserted between F9 and F8, the pin has to be inserted on the "outer" side (distally) of each primary/secondary to be measured (Figure 6.11). For wing-shape, read feather length to the nearest $0.5 \mathrm{~mm}$.

It does not matter how the ringer holds the bird and which wing is measured."

For more detailed description of the method see feather-length measurement description.

Comments: Firstly, as stressed previously in the description above, this is not the wing-shape measurement but rather a set of ten independent measurements of ten bird feathers. This is easily done and the result, obviously, may be elaborated on according to specific needs. However, the lengths of subsequent primaries do not describe the wing-shape, as they are located at different angles and in different places along the carpal part of the wing, so the real wing-shape is derived from both, (1)

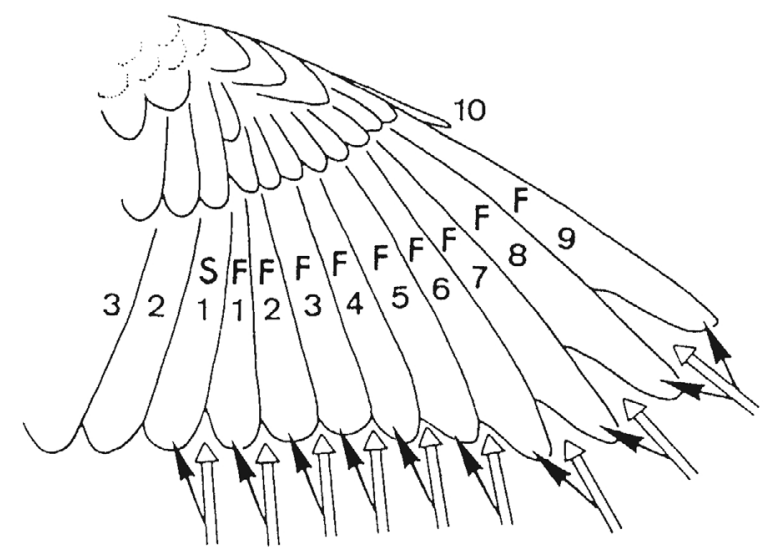

Figure 6.11: Idea of the wing-shape measuring (after Jenni and Winkler 1989, from Bairlein, 1995). 
lengths of subsequent feathers and (2) peculiar features in their distribution along the wing. Secondly, the measurement of the outer primary is taken from the other side of the feather, which means that it is not comparable with the other measurements. The primaries extend in a step-like fashion along the wing so, the measurement "from below" is not equal to the measurement "from above" of the feather (i.e. the edge of the feather that points rostral vs. caudal). Apart from writing comments to the featherlength measurement (which should also be done here), this method is extremely time consuming, so in practice, it is not useful when ringing a lot of birds.

\section{Bill-length measurement}

The usefulness of bill-length measurement differs very much in various groups of birds. This is a standard (and very useful) measurement in waders, but it is of a very limited value in passerines. It can be done using callipers or dividers as shown at Figure 6.12.

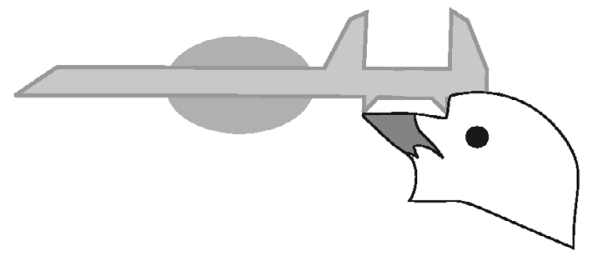

Figure 6.12: Measurement of the bill-length to the skull in passerines.

\section{Tarsus-length measurement}

The usefulness of tarsus-length in biometrical studies also differs greatly, and although it may be useful in wader studies, nobody has shown the same for migrating passerines. However, there are papers showing the tarsus-length to be useful as an additional measurement for certain species. For example, it is used as an index of a body size in special studies on breeding populations.

In passerines, two methods are used.

Measuring with dividers, as given in The Ringer's Manual (Spencer, 1972): “The measure is taken from the depression in the angle of the inter-tarsal joint (the "knee") to the base of the last complete scale before the toes diverge (Figure 6.13A). It is the length of the tarso-metatarsal bone that is measured. It is recommended that the tarsus should normally be measured to the nearest $0.5 \mathrm{~mm}$, but to the nearest $1 \mathrm{~mm}$ in species with tarsi measuring $60 \mathrm{~mm}$ or longer."

Measuring using callipers is presented in Manual of Field Methods (Figure 6.13B): "The following instructions for measuring tarsus are for a right handed person. For a left handed person: reverse left and right hands. The position of the right leg of the bird will be somewhat different. Use easily running slide callipers, and be careful not to bend the tibiotarsus. 
A

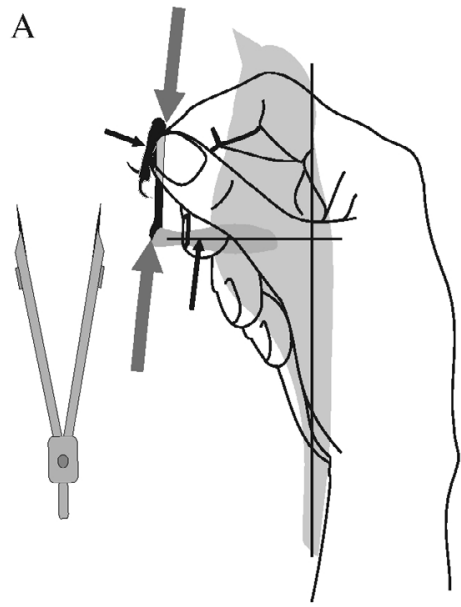

$\mathrm{B}$

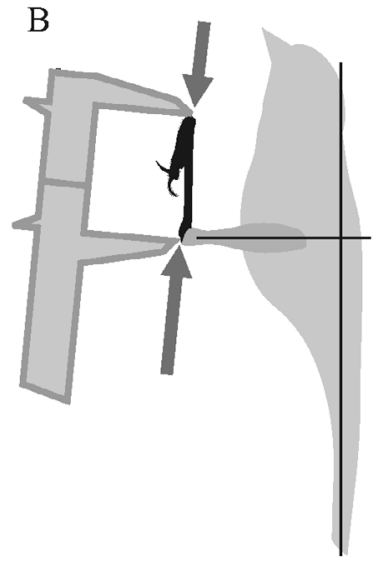

Figure 6.13: Two methods of the tarsus-length measurement. A - using dividers, B - using callipers.

1. Take the bird, lying on its back, in your left hand with the bird's head between your index finger and your middle finger.

2. Hold the right (meta)tarsus between thumb and index-finger, fold the toes backwards and also hold them between thumb and index-finger. For birds with a very short tarsus one should use the extreme tips of the fingers.

3. Position the tip of the middle finger behind the tibiotarsus, such that the tibiotarsus makes a right angle to the body and the metatarsus makes a right angle to the upper part of the leg. This positioning greatly improves the within and between observer repeatability of the measurement.

4. Make the measurement from the notch on the metatarsus to the top of the bone above the folded toes (Figure 6.13B), and read the callipers to $0.1 \mathrm{~mm}$ ”.

\section{Muscle-score}

Description after Manual of Field Methods (Barlein, 1995) (Figure 6.14): "Beside fat, which is the primary energy fuel for migrating birds, migrants also use muscle proteins in flight. The size of the breast muscle is a further valuable indicator to body condition of migrants. In birds whose flight muscles are not covered by fat, the shape of the breast muscles can be easily recorded and scored. Muscle score is assessed visually and by sweeping the thumb over the sternum”.

Comments: It seems that this scoring is useful for the birds of low (or very low) fat reserves. In assessing the muscle-score, one must remember that there are distinct and specific differences pertaining to breast muscle appearance: some species have nearly always a "good look" while others always have a "slim" appearance. 


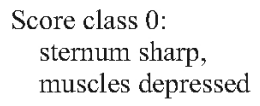

Score class 3:

sternum difficult to distinguish due to rounded (full) muscles
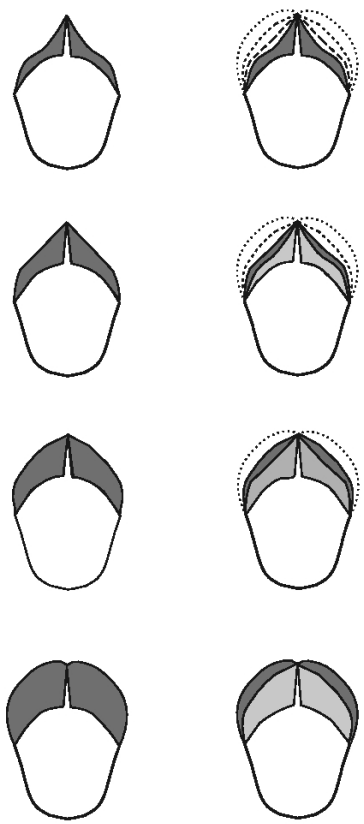

Figure 6.14: Muscle scoring (after G. Wallinger from Bairlein, 1995 modified).

\subsection{Special Studies}

\subsubsection{Directional Preferences of Nocturnal Migrants}

The described method of studying directional preferences in nocturnal migrants includes a new field technique (Busse's flat cage - Busse, 1995) and pays special attention to the inconsistency of directional behaviour pattern in individual birds. It may be used under real field conditions, by professionals as well as amateurs. The equipment is simple and cheap, and the technique easy to learn in a standardized format. Additionally, the test routine allows for the collection of large amounts of data (since tests may be performed both at night and at day). Diurnal tests under an overcast sky have the same value as tests done with good sky visibility, but this is not the case in nocturnal tests. Analysis of local vectors of directional behaviour patterns seems useful in studies on local migratory directions and on the overall population composition of migrants.

General idea of the flat cage. A bird tested in the flat cage inside of the screen is cut off any visual cues but the sky only. The protection screen (see Figure 6.15 for dimensions) idea was shown in Figure 3.9 (screen partly removed on the picture to show the cage inside). 
The testing stand. The place of tests should be a flat area (top of a hill, etc.) without trees, wires, or poles that may be seen by a bird above the protecting screen (Figure 3.10.)

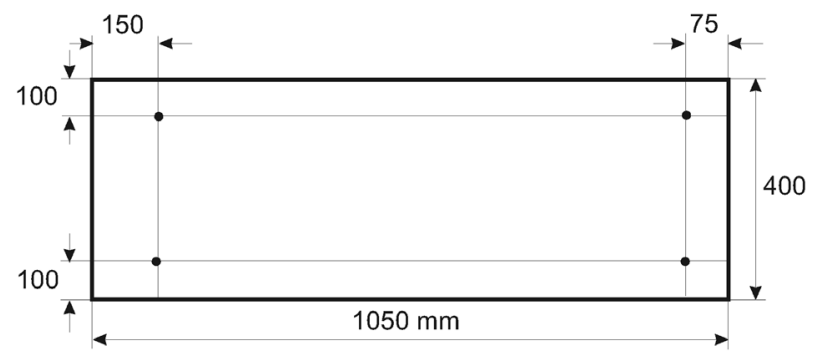

Figure 6.15: Dimensions of the one of four segments building the protective wall at the orientation tests stand.

The testing routine. Tests can be done at any time, both night and day. There are meteorological limitations, so tests should not be done with rainfall or snow (nor with wet fog) causing condensation on the foil of the test cage. Tests are not recommended with wind force exceeding $5^{\circ}$ Beaufort.

Caught birds can be tested immediately after catching and ringing, or they can be kept in opaque bags or cages for at most two hours.

1. Preparation of the cage for the test includes covering its vertical sidewall with a strip of foil from a roll of width adjusted to the height of the cage (with an extra $2 \mathrm{~cm}$ for folding - Figure 6.16). Details of the procedure are given in Figures 6.17-6.18. Fix the beginning of the strip to one of vertical wires of the cage with transparent sticky tape, and then cover the side of the cage with straightened foil, fixing its upper end. Finally, cut the strip off of the roll after connecting the ends. The foil should be carefully handled to avoid making scratches, holes etc.
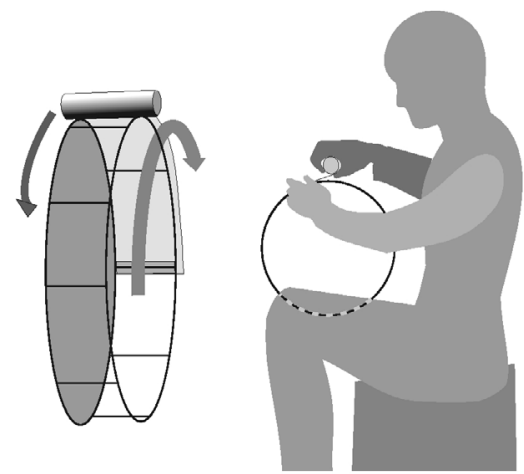

Figure 6.16: Putting-on foil on orientation tests cage - this is the only effective position for a person performing this task. 

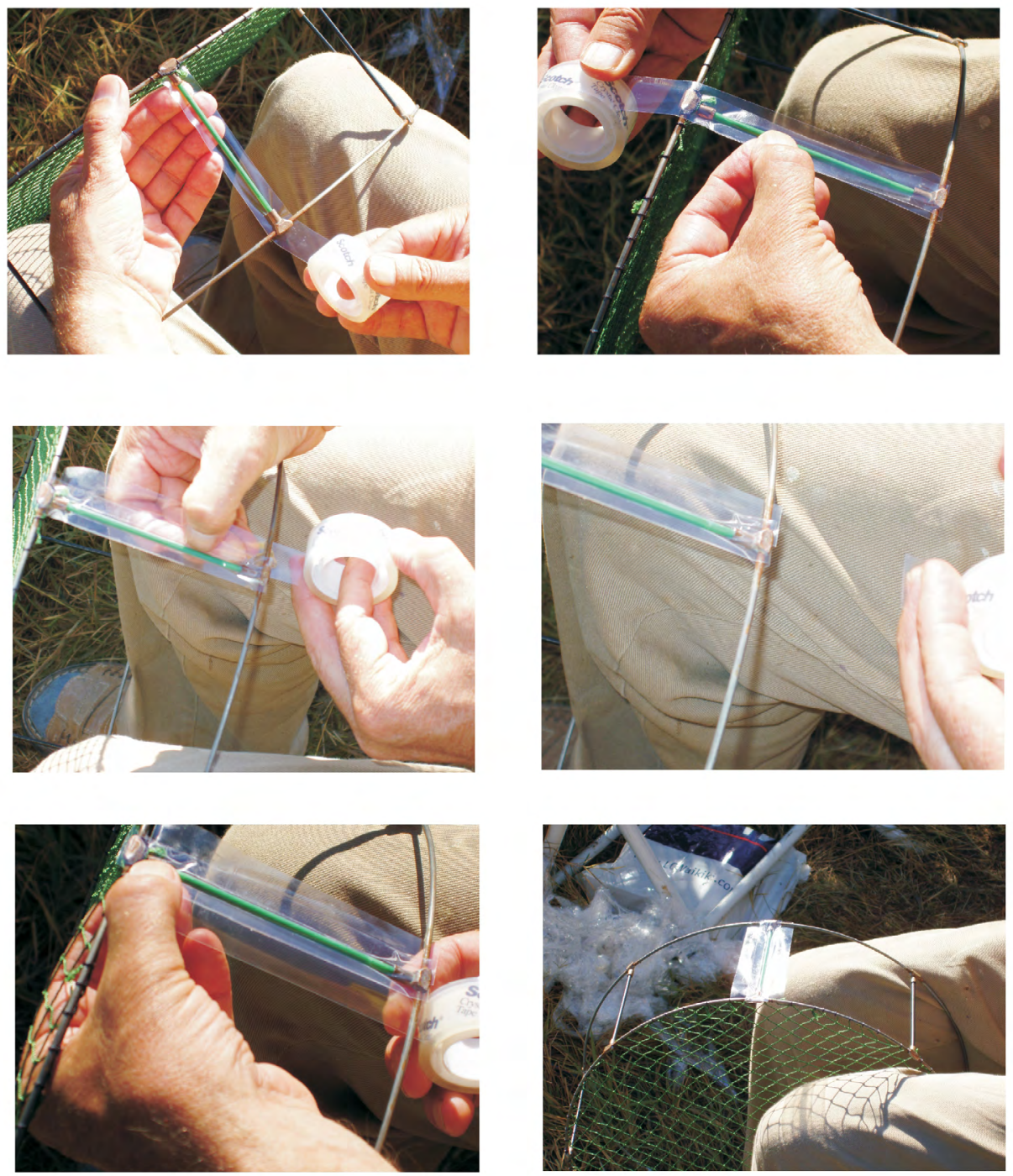

Figure 6.17: Preparing a cage for the test - first step (creating the starting stick; description in the text).

(which could subsequently be taken for the signs of bird activity). The cage may be prepared in advance, but extended storage of the cages in moist air is not recommended since the sticky tape used to fix the foil may come loose.

2. Transport the bird to the test stand in an opaque bag or cage, remove it below a top of the protecting screen and put it into the test cage inside the screen (Figure 6.19-1). The direction the bird enters the cage does not seem to influence the results, but the custom of putting it from one side (e.g. always from the south) could be a rule. 

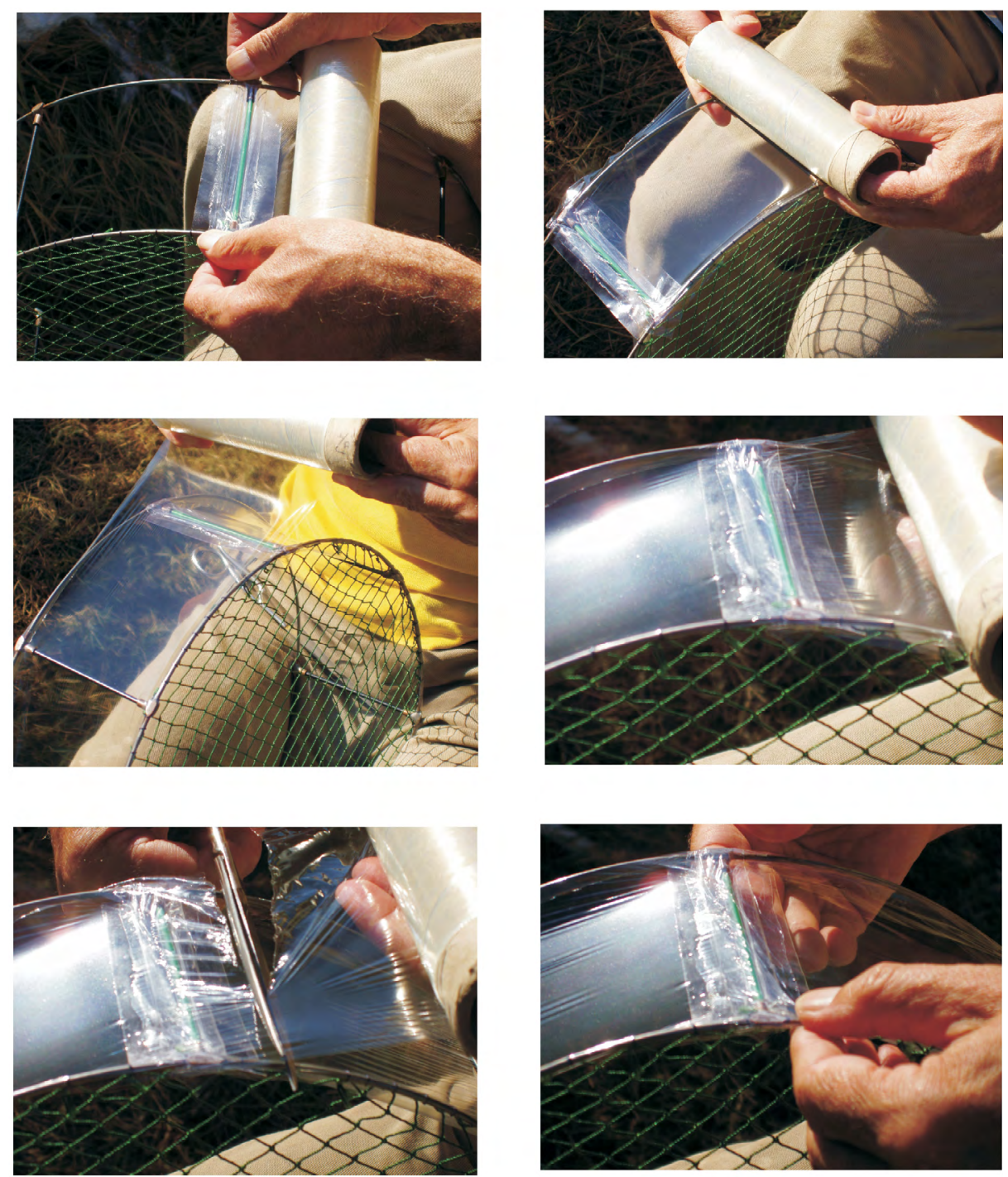

Figure 6.18: Preparing a cage for the test - second step (covering the side wall with foil; exact explanation in the text).

After inserting the bird, the observer should leave the place quickly and note the time (precision 1 minute), and after the agreed test time (10 minutes proposed as standard), quickly return and remove the bird from the cage. If the bird is earmarked for other tests, it must be caught by hand (which is not too easy and many escape). During the test time, the bird should not be disturbed by sudden noises or things coming into visibility. When larger birds as thrushes are tested, the cage should be fixed to the ground so fluttering does not displace the cage. 


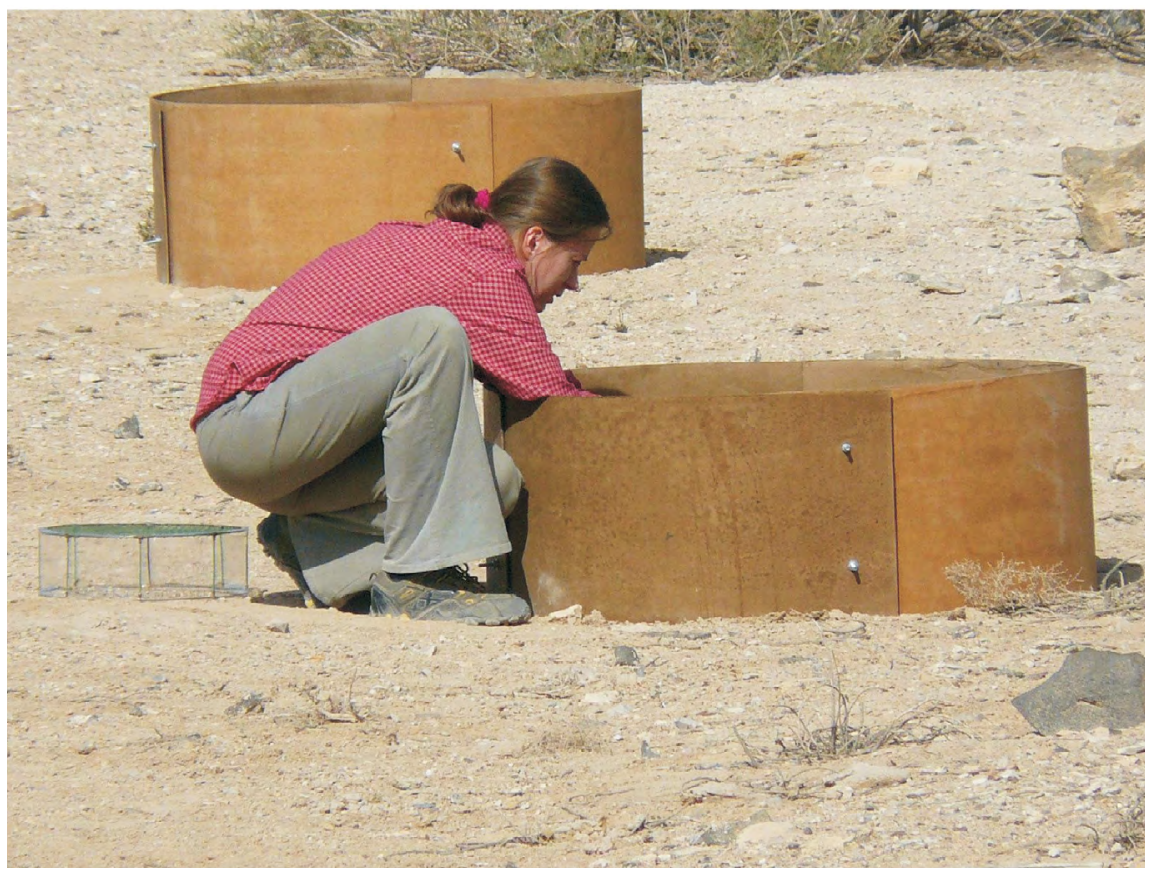

Figure 6.19-1: Putting a bird into the cage. Note that operation is done below the top of the protecting wall. Azraq, Jordan. Photo P. Busse.

3. The test cage is at the centre of the protecting screen (Figure 6.19-2) with one of the wires directed to the North (indicated by a previously fixed pole outside of the screen, not visible to the bird). It is always handy to direct the wire where the foil strip is fixed (to the North); this prevents misidentification of sectors when noting the results. Putting the cage on a flat, symmetrical piece of carton without a slimy surface is highly recommended.

4. After the test, the results of the test should be noted. Count signs of the bird activity sector by sector. Starting always from NNE direction is convenient when you handle the cage (with its bottom side to your belly, Figure 6.20-1). Count the signs of activity: holes and dots made by bill as well as holes and scratches made by claws of bird when it hopped against the foil. Sometimes, signs of different origins are not easy to separate, so counting them altogether is the best solution. The behaviour of the bird in a cage is, to some extent, species-specific, and in one species, bill signs are more common, while claw marks may be the majority in another. Some practice is needed, but individual differences between observers, if they do exist, concern the number of counted signs and not their distribution. Every counted sign must be instantly marked with colour marker to avoid double counts. It is a good custom to write numbers on the foil first and then rewrite them into the form. 


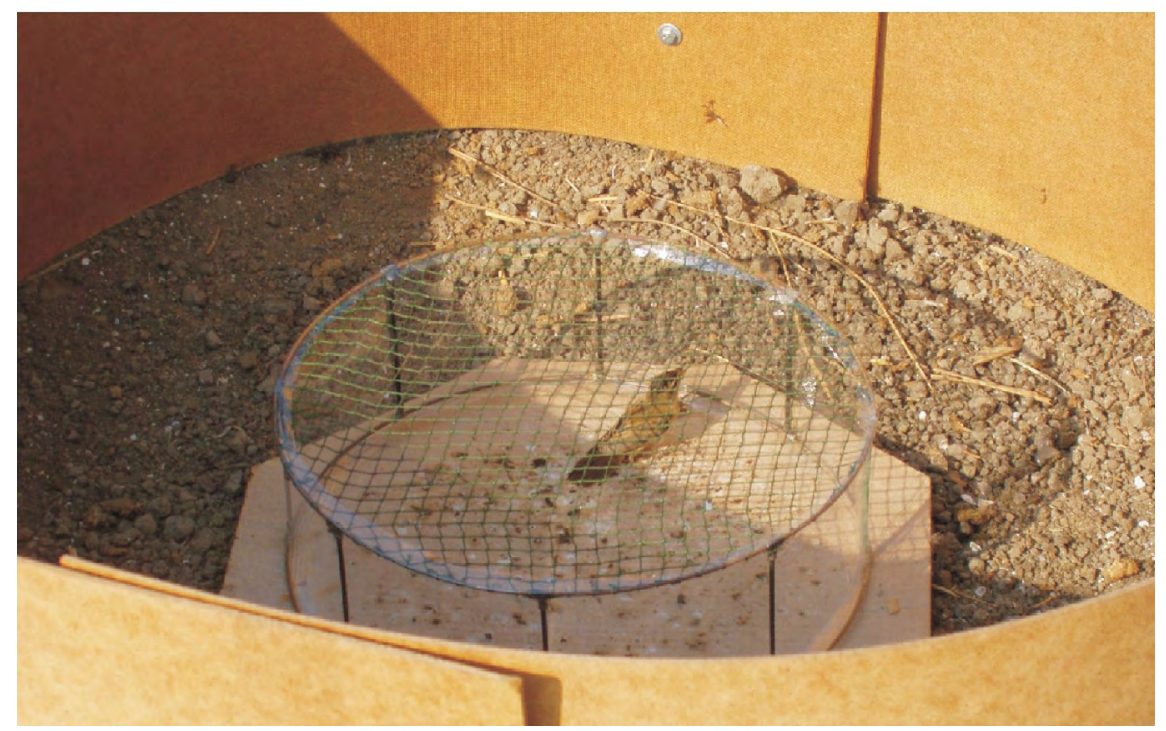

Figure 6.19-2: A bird in the cage. Note bottom plate and details of the wall construction. Burullus, Egypt. Photo P. Busse.
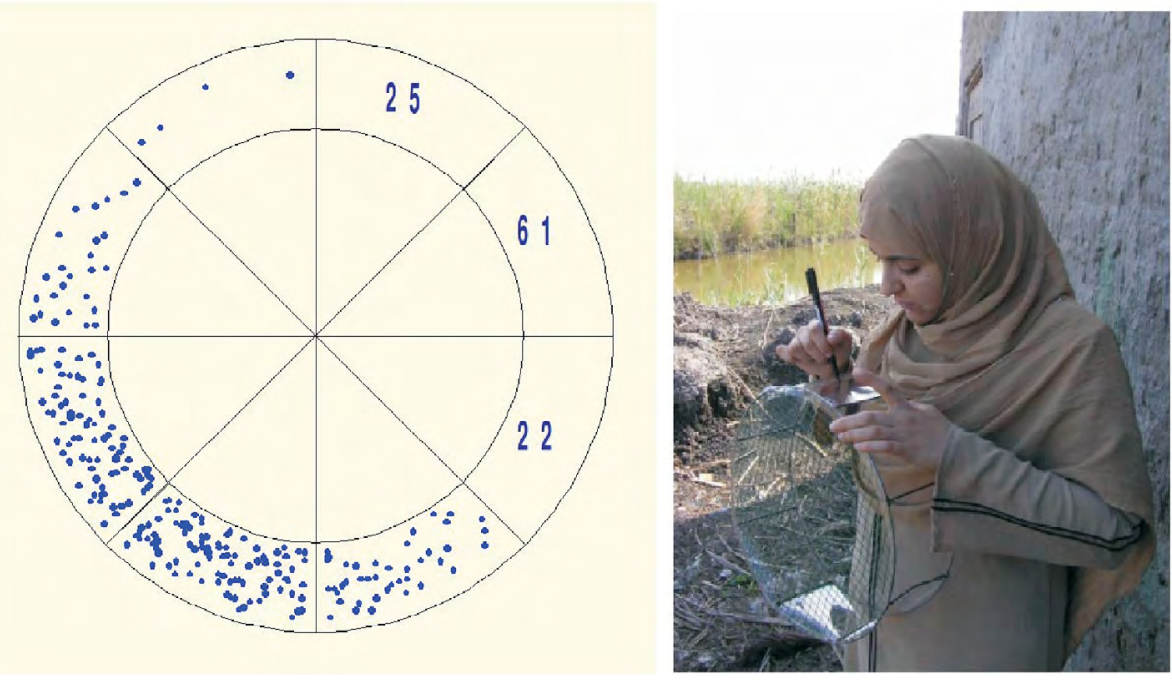

Figure 6.20-1: Counting the scratches on the foil. However, an advice is to do this sitting. Burullus, Egypt. Photo P. Busse. 


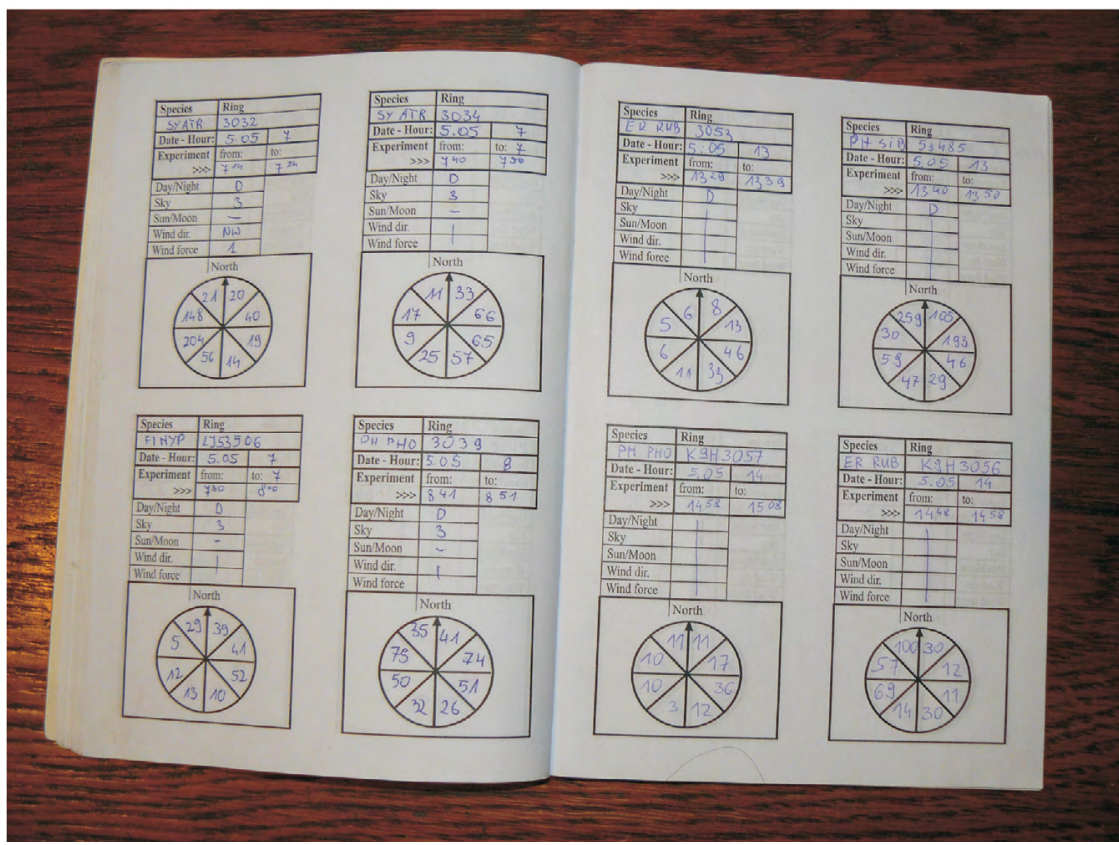

Figure 6.20-2: A special note-book with results of eight tests.

Note that, if you handle the cage as recommended above, the correct direction of writing into the circular data form is opposite (Figure 6.21).

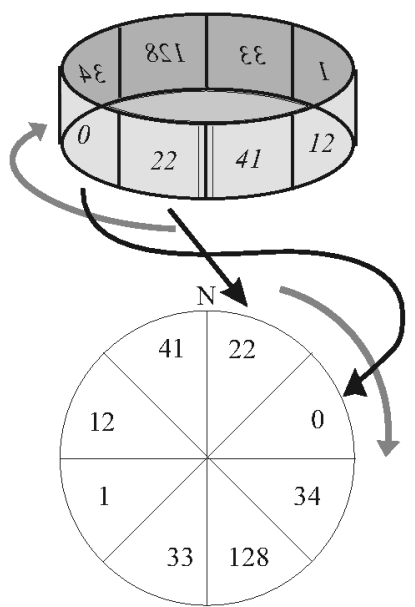

Figure 6.21: Noting the results of the orientation test. 
Longer storage of cages before counting is not recommended because one may risk accidental damage of the foil. However, as it is easier and quicker to count the signs made by the bird in good light conditions, cages from the night tests may at least be stored till next morning, if there are enough cages for all planned tests. Used foils cannot be handled or stored after removing them from the cage.

5. Filling out the test form includes a couple of boxes with information complementary to the main data (Figure 6.22):

Species, Ring number, Status (A - freshly ringed, first test, B - next test; R retrap), Sex/age, Fatness (the fat-scale used is specified separately), Date - hour of catching, test time (from - to, given as hour and minutes), Day/night (D, N), Sky visibility (0 - none, 1 - small: cloudiness 7 to 9, 2 - medium: 4 to 6, 3 - good: 0 to 3), Sun/Moon (S - the Sun, M - the Moon visible, ,-" none of them), Wind direction (accuracy to $1 / 8$ of the wind-star; 0 - no wind), Wind force ( 0 - no wind, $1-1^{\circ}$ to $2^{\circ}$ Beaufort, $2-3^{\circ}$ to $4^{\circ} \mathrm{B}, 3$ - over $4^{\circ} \mathrm{B}$ ).

\begin{tabular}{|c|c|}
\hline Species & \\
\hline Ring & \\
\hline Status & \\
\hline Sex/Age & \\
\hline Fat-Weight & \\
\hline Date-hour & \\
\hline Experiment & from \\
\hline Day/Night & \\
\hline Sky & \\
\hline Sun/Moon & \\
\hline Wind dir. & \\
\hline Wind force & \\
\hline
\end{tabular}

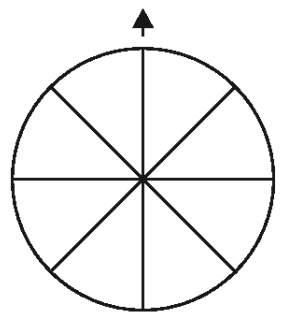

Figure 6.22: Orientation tests - the data form.

After filling up the test form, the foil is removed from the cage, and the cage may be prepared for the next test. One single person working at one test stand may, without problems, handle six birds per hour, including the need to count results and prepare the next cages, as long as the test stand is not too far from the ringing site. Working two stands is possible for an experienced person, otherwise, it requires some help from a second person. 


\subsubsection{Additional tips}

1. Building up the screen

A. The screen is built from four pieces of solid elastic plates. Every part of the screen is identical, with four holes for screwing them together (Figure 6.15).

Note, however, that at one end, holes are farther (end A) from the shorter side of the plate than at the second end (end B).

B. For preparing parts for connecting - lay them in one row with ends A laying $\mathrm{ON}$ ends B. The upper part of this strip will be inside of the screen. Connect parts, using screws, with their heads inside of the screen. We suggest using thumb-nuts. This makes a long strip of four parts together.

C. Connect the beginning with the end of the stripe using screws in the same manner: end A of the last part must be INSIDE the round screen.

\section{Preparing the cage}

Put rods into holes in a circular cover of a cage (this with a net) and fix them by pressing or beating using a piece of wood. Put circular base on rods and fix them using the piece of wood. For longer transport, you can remove rods.

\section{Covering the cage with a foil}

A. Note that one of the rods is a different colour from than the rest. Use it as the beginning and the end of the foil, for fixing see point 3B, it will be located North!

B. Use transparent sticky tape about $20 \mathrm{~mm}$ wide:

1. Start fixing this tape from top end of the rod inside of the cage but with sticky side outwards (the rod must be placed symmetrically); the tape should go around base circle wire and return to the top of the rod: both inner and outer parts are fixed together making a base for fixing "wings".

2. Make "wings" by sticking the tape from inside on both sides of the base: you have two sticky wings along the rod.

3. Fix the cage between laps as on Figure 5.4, fix the beginning of a foil stripe to one of wings, cover all sidewalls with strengthened foil and fix it to the second wing. Cut off the foil, but with some margin to cover second wing too.

\subsubsection{The Study of Moult}

Moulting strategies and the timing of moult are highly varied, depending on the population. Since various populations migrate all over Europe and the Middle East, records of moult in migrants offer many possibilities for interesting moult studies. One course of action is to collect moult data using "moult cards". The moult card design for passerines and its filling-up rules are presented below (Figure 6.23) after instructions of the Swiss Ornithological Institute: 


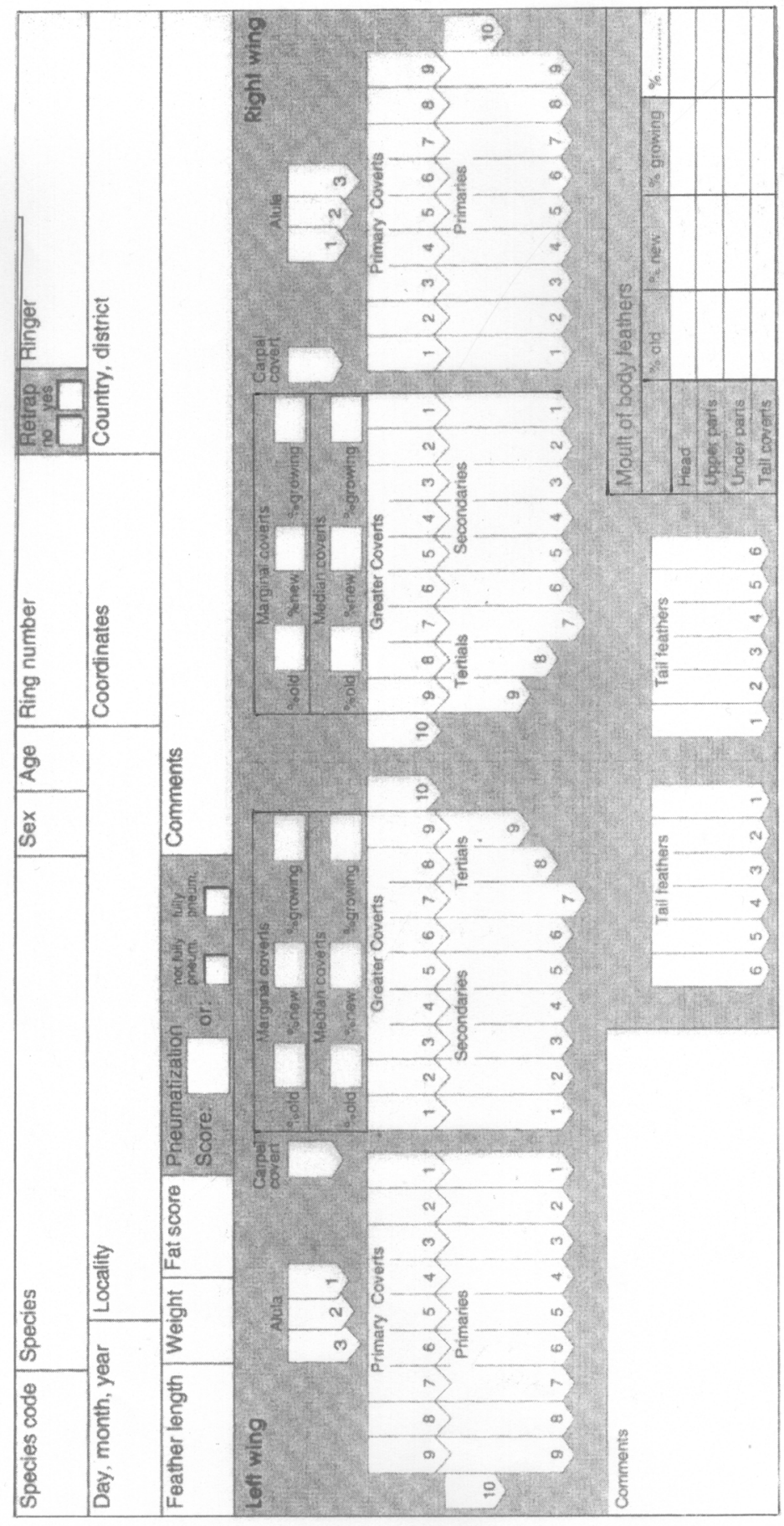

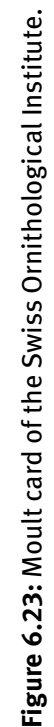


"This moult card shows both wings. For general use, fill in moult cards for every bird belonging to one of following categories:

1. In summer/autumn: All adults in moult and all adults having renewed part of the plumage; all first-year birds with growing or renewed secondaries or primaries.

2. In winter/spring: All birds in active moult of primaries, secondaries, tertiaries, rectrices or greater coverts; all birds after moult with renewed secondaries or primaries.

If possible, record all feathers, but data for restricted tracts only (e.g. primaries and secondaries) are welcome as well.

\section{General information (first three lines)}

Sex/age

Feather-length, weight, fat score: this is optional on ringing stations where this information is recorded in the ringing lists.

Skull pneumatization: This is important additional information. Give either score or tick the appropriate box.

\subsubsection{Moult Data}

Always fill in one side (wing and tail) completely. If time allows, complete both sides, especially if they are different or deviate from "normal" moult patterns. If you hold the bird with the head towards you, you might turn the moult card.

Write codes into the white feather boxes. Use horizontal lines to indicate that the same code applies for a series of feathers.

Give the approximate percentage of old, new and growing feathers for body feathers, marginal ("lesser") and median coverts. If body feathers are composed of three generations, the additional column may be used (explanations in the comment section).

Codes: The aim is to assign each feather to the moult when it has been grown. Codes 0 - 5 are the same as those used in the BTO moult card.

0 - old

1 - feather missing or pin

2 - feather just emerging from sheath or up to $1 / 3$ grown

3 - feather between $1 / 3$ and $2 / 3$ grown

4 - feather more than $2 / 3$ grown, but still not full grown or with trace of sheath remaining at base

5 - renewed in summer/autumn in the breeding range (postbreeding/postjuvenile moult)

6 - renewed after autumn migration during (late autumn) winter/spring ("prebreeding" moult)

7 - In winter/spring: older than 6 , either 0 or 5 . This code may be used in winter/ spring for feathers that appear much older than 6 , but for which it is uncertain whether they have been acquired during the postjuvenile/postbreeding moult or earlier; In summer/autumn: older than 0 . This code may be used in late 
summer/autumn for feathers, which have been retained during the previous prebreeding moult (e.g. adult Spotted Flycatcher, Golden Oriole)

8 - older than 6 , either 5 or "early 6 ". This code may be used in winter/spring for feathers which appear somewhat older than 6 , but for which it is uncertain whether they have been acquired during the postbreeding/postjuvenile moult before autumn migration or during an early "prebreeding" moult in late autumn/winter

9 - impossible to assign”.

\subsection{Field Ringing/Data-Collecting Form}

Field data collecting forms used in the station work are specially designed sheets bound into field-books, which prevent accidental loss or damage and allow easy handling of the contents, both in the field and for data input.

Note: It has been suggested that field data can be directly entered into laptop computers, but such a procedure is extremely unsafe because of high vulnerability to typing errors - everybody, even accidental helpers, is capable of writing numbers and text to the form in a correct way, while only well trained people can type quickly, and accurately, on a keyboard.

The Network basic data form contains a space for main ringing data, a standard set of measurements/scores and additional data fields for optional data collected at the particular station.

Filling-up the ringing field-book:

1. The cover page (Figure 6.24) -

- Station symbol

- Year

- Season (spring - autumn)

- Running number of the field-book

Note: there could be up to three field-books used simultaneously, numbered separately: two for the most commonly used ring sizes (types - see below) and the third - for all other ring types. One field-book, for all used rings, can be used as well, but this would be more time consuming to input into a computer.

- Date and hour of the first and last item noted

- Ring type and ring numbers (from - to) included into this field-book

- A box filled-up when data are already entered into a database (signed by the person who entered the data).

2. The front page (Figure 6.25) has a space for listing the ringers, with their codes written to the form and their periods of ringing. It is highly recommended to have only one responsible ringer at a time.

Special events affecting ringing,e.g. extreme weather conditions, loss of nets, low number of staff, etc., should be noted in the lower table on this page. 
SE EUROPEAN BIRD MIGRATION NETWORK

\begin{tabular}{|c|c|c|c|}
\hline Station & Year & Season & No. \\
\hline \multicolumn{4}{|c|}{ RINGING } \\
\hline From: & \multicolumn{2}{|c|}{ To: } & \\
\hline Date & & Date & \\
\hline Hour & & Hour & \\
\hline \multirow[t]{8}{*}{ Ring type } & \multicolumn{3}{|c|}{ Ring numbers } \\
\hline & \multicolumn{3}{|c|}{-} \\
\hline & \multicolumn{3}{|c|}{-} \\
\hline & \multicolumn{3}{|c|}{-} \\
\hline & \multicolumn{3}{|c|}{-} \\
\hline & \multicolumn{3}{|c|}{-} \\
\hline & \multicolumn{3}{|c|}{-} \\
\hline & Data inp & & \\
\hline
\end{tabular}

Figure 6.24: Bird ringing notebook - cover page.

\begin{tabular}{|l|l|l|l|}
\hline CODE & Name & From (date. hour): & To (date, hour): \\
\hline & & & \\
\hline & & & \\
\hline & & & \\
\hline & & & \\
\hline & & & \\
\hline
\end{tabular}

SPECIAL EVENTS affecting ringing (extremal weather conditions, loss of nets etc.)

\begin{tabular}{|l|l|}
\hline Date & Details \\
\hline & \\
\hline & \\
\hline & \\
\hline & \\
\hline & \\
\hline & \\
\hline & \\
\hline & \\
\hline & \\
\hline & \\
\hline & \\
\hline
\end{tabular}

Figure 6.25: Bird ringing notebook - front page. 
3. The main data sheet is spread into two neighbouring pages (Figure 6.26). Each individual set of data is written on one row, divided into columns containing the data in a sequence. The division is adjusted to the sequence dictated by the ringer (see Laboratory Working Routine - p. 118).

The same sheet is used for both ringings and retraps/controls - this simplifies input of the data and saves time.

Each column is characterized by one of three special proprieties, symbolized by a special character below the column head:

I - vertical strokes or lines are allowed when the content in subsequent rows is repeated. This speeds up the filling of columns containing data frequently repeated for many individuals: hour, net no., species code and sex,

o - vertical strokes are not needed in the column: Date is default, the same as at the beginning of the page unless part of a page is demarcated by a horizontal line and a new date is entered. Ring type and ring series are by default the same unless specified by new input. Ring number must be filled for all individuals. Status is empty by default for all newly ringed birds. Ringer code is assumed to be the same for all records on the page unless the ringers change.

$\mathbf{x}$ - vertical strokes or lines are not allowed in the column - in some cases (Age, Fat) a stroke could be misread later as letter "I" or number " 1 " or when repetition of the same value is rather rare (Wing, Tail, Weight).

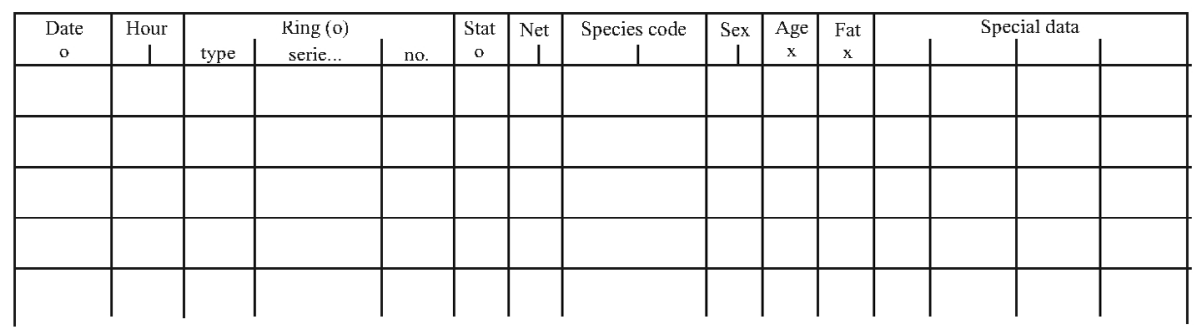

\begin{tabular}{|l||l|l|c|c|c|c||c|c|c|c|c|c|c|}
\hline \multicolumn{9}{|c|}{ Wing-formula $(\mathrm{x})$} & $\begin{array}{c}\text { Wing } \\
\mathrm{x}\end{array}$ & $\begin{array}{c}\text { Tail } \\
\mathrm{x}\end{array}$ & $\begin{array}{c}\text { Weight } \\
\mathrm{x}\end{array}$ & $\begin{array}{c}\text { Rngr } \\
\mathrm{o}\end{array}$ & $\begin{array}{c}\text { Comments } \\
\mathrm{o}\end{array}$ \\
\hline (tip) & & & & & & $(8)$ & & $(10)$ & & & & & \\
\hline
\end{tabular}

Figure 6.26: Bird ringing notebook - left and right pages. 
Subsequent columns contain:

Date - formats allowed: e.g. 1.9, 1.09, 01.09 (Sept. 1st); it must be written at the beginning of every page and when the next date starts.

Hour - formats allowed: e.g. 6 or 06 (for a nets control at 6.00); full hours only.

Ring type - one or two letters (or up to two digits when ring type is described by first number digits); when only one type of rings is noted within a sheet, only the first box on the sheet should be filled. When more types are present, write the type when changed; at retraps and controls, write the type in each case.

Series - newly ringed bird: all digits of a number except last two; if only one type of rings - write only once at the beginning of a page; retraps and own controls: write full ring number here.

No. - newly ringed bird: last two digits of the ring number; retraps and own controls: leave empty.

Stat. (status) - at Operation Baltic and SEEN stations there are used two groups of codes, while some other status code systems could be used.

1. Birds caught within normal routine work

- Leave empty for newly ringed bird,

$\mathrm{R}$ - Retrap (a bird ringed within the same season),

$\mathrm{C}$ - Control (a bird ringed elsewhere in the country or at the site during previous seasons),

$\mathrm{V}$ - Foreign bird control,

$\mathrm{N}$ - Released without ring,

D - Bird dead during catching/ringing, this code letter could be added to any other code, forming two-letter code, e.g. $\mathrm{RD}$ - retrap dead.

There are a few sporadically used codes for the bird status:

$\mathrm{Z}$ - Ring changed, A - ring added are used exceptionally when existing ring is damaged or heavily worn (if it is possible to remove it without risk of injuring the bird: change the ring, if not: add another ring on the second leg). Never put the second ring on the same leg.

2. Birds obtained outside of the standard catching procedure (found, caught accidently, brought by visitors, etc.)

F- All such special cases when the bird will be not counted to migration dynamics data,

$\mathrm{X}$ - None of the above listed,

$\mathrm{D}$ - Code is applicable as a second letter.

Net (optional) - net number (if appropriate) or net symbol (if special net type)

Species code - five or six letter code.

Sex - M (male), F (female) or zoological signs ( $\hat{\partial}$, + ); leave empty when not known.

Age - J (juvenile), I (immature), A (adult), N (not defined) (see p. 87)

Fat - fat score $0-8$ (see p. 95) 
Special data - optional, according to the station needs.

Wing-formula - (tip) - numbers of primaries (ascendant) being the wing-tip, e.g. 3, $34(3=4), 35(3=4=5)$ etc. Distances of subsequent primary tips in relation to the wing tip;

For outer (distal) primary measurements, add " 0 " (zero) at the beginning;

When distal and proximal primaries are equal, write the same number in two subsequent boxes;

(8) Last box when standard (to the eight primary) method used.

Wing, Tail - write in full millimetres.

Weight - formats allowed: e.g. 16 or 16.0 depending on accuracy of measurement (to the nearest gram or to the nearest $0.1 \mathrm{~g}$ respectively).

Rngr - ringer code (once per a sheet when no changes).

Comments - plain text comments or the station free use. 